\title{
Impact of Asian Dust Aerosol and Surface Albedo on Photosynthetically Active Radiation and Surface Radiative Balance in Dryland Ecosystems
}

\author{
X. Xi and I. N. Sokolik \\ School of Earth and Atmospheric Sciences, Georgia Institute of Technology, 311 Ferst Drive, Atlanta, GA 30332-0340, USA \\ Correspondence should be addressed to I. N. Sokolik, isokolik@eas.gatech.edu
}

Received 15 January 2012; Revised 24 February 2012; Accepted 25 February 2012

Academic Editor: Dimitris G. Kaskaoutis

Copyright (C) 2012 X. Xi and I. N. Sokolik. This is an open access article distributed under the Creative Commons Attribution License, which permits unrestricted use, distribution, and reproduction in any medium, provided the original work is properly cited.

We investigated the extent to which Asian dust can affect vegetation in dryland ecosystems through altering photosynthetically active radiation (PAR) and shortwave and longwave radiation components of the surface energy balance. Results show that dust decreases the surface radiative balance and total PAR. The diffuse component of PAR, however, increases with increasing dust load but then decreases after reaching a maximum at a certain optimum condition. The forcing efficiency ranges from -67.7 to $-82.2 \mathrm{Wm}^{-2} \tau_{0.5}{ }^{-1}$ in total PAR and from -68.8 to $-122.1 \mathrm{Wm}^{-2} \tau_{0.5}{ }^{-1}$ in surface radiative balance. The ratio of total PAR to downwelling shortwave flux remains nearly constant $(0.45 \pm 4 \%)$ similar to other aerosol types, while the ratio for the diffuse faction of PAR exhibits significant variations. The impact of dust on the gross photosynthetic rate varies among different types of crops. C4 plants such as corn tend to be less sensitive to the dust optical properties compared to C3 plants such as soybean and wheat.

\section{Introduction}

There has been a growing interest in the impact of atmospheric aerosols upon the terrestrial ecosystems and their role in land-atmosphere interactions in the context of earth system science. These interactions are thought to involve multiple, interrelated processes and various feedbacks that remain poorly constrained [1]. Here we address the impact of mineral aerosol (dust) that involves the radiative transfer processes, focusing on aerosol-induced changes in photosynthetically active radiation (PAR, $0.4-0.7 \mu \mathrm{m}$ ) and surface radiative balance (SRB, $0.3-20 \mu \mathrm{m}$ ). Light is a vital factor governing the plant photosynthetic activities, and hence changes in PAR caused by aerosols can influence the plant-air carbon/water exchanges and ecosystem functioning. Changes in the land surface energy balance are important because they affect the surface evapotranspiration, sensible and latent heat, soil temperature and moisture, and major landatmosphere exchange processes that along with light availability are all important to the ecosystems.
Dust can affect both the shortwave (SW, $0.3-2.5 \mu \mathrm{m}$ ) and longwave (LW, 2.5-20 $\mu \mathrm{m}$ ) components of the radiative energy balance, but in opposing ways [2]. Based on regional model simulations, Mallet et al. [3] found that dust aerosol decreased the SW radiation by up to $-137 \mathrm{Wm}^{-2}$ (regional mean) in North Africa, resulting in a significant decrease in surface temperature and sensible heat. Based on a study with a coupled aerosol transport-radiation model, Takemura et al. [4] reported that dust caused a monthly mean SW surface forcing of $-2.0 \mathrm{Wm}^{-2}$ over East Asia, where the surface forcing was defined as the difference in SW fluxes between clean and aerosol-laden conditions. Using satellite observations in conjunction with modeling, Huang et al. [5] found that dust aerosol caused a daily-mean surface SW forcing of up to $-41.9 \mathrm{Wm}^{-2}$ over the Taklamakan desert.

In contrast to the reduction in SW radiation, dust significantly increases the LW radiation reaching the surface. For instance, based on ship-based measurements during the ACE-Asia campaign, Vogelmann et al. [6] demonstrated that Asian dust contributed to a surface LW forcing of up to 
$10 \mathrm{Wm}^{-2}$; Markowicz et al. [7] found that the LW forcing compensated about $20 \%$ of the SW cooling. Huang et al. [5] found that about one-third of the SW surface cooling caused by Asian dust was compensated by its LW warming effect. Thus, dust-induced changes in both the SW and LW radiation should be accounted for in assessing the surface energy balance.

Although there have been numerous studies of the dust SW and LW radiative impact, we are not aware of any study that comprehensively addressed the impact of dust on PAR. Past studies, however, explored the influence of several other aerosol types on PAR, including volcanic aerosol $[8,9]$, urban pollution aerosol [10-12], and biomass burning smoke [13]. Several studies reported reductions in the plant photosynthetic rate and primary production due to less incoming PAR as a result of aerosol attenuation $[10,11]$. However, while reducing the total PAR, aerosols can enhance the diffuse fraction of PAR and lead to a higher gross photosynthetic rate. The underlying reasoning is believed to be due to the redistribution of light between the sunlit and shaded leaves within the plant canopy: the aerosol absorption and scattering causes reductions in the PAR received by the sunlit leaves with no change or some reductions in the photosynthesis, while more scattered diffuse PAR becomes available to the majority of light-limited shaded leaves, such that the gross photosynthetic rate increases. This so-called "diffuse radiation fertilization" effect due to aerosols is well demonstrated in modeling $[12,14]$ and observational $[9,13,15]$ studies.

Given that changes in total PAR and its diffuse fraction are controlled by the aerosol type, especially by aerosol burden and optical properties and because of distinct differences between the optical properties of dust and other aerosols, it is important to understand how dust aerosol can affect PAR. Furthermore, dust-induced changes in both PAR and SRB need to be addressed to understand the net radiative impact of dust on terrestrial ecosystems. Indeed, concurrent with the modifications of PAR, aerosols can alter the surface net radiation, latent/sensible heat, soil/leaf temperature, and atmospheric humidity, which can also affect the photosynthesis and respiration processes and the net primary production (NPP) $[16,17]$.

The focus of this paper is on dust in East Asia. This region is vulnerable to the dust impact because of vast and prodigious dust sources. Each year large quantities of windblown dust are being emitted from arid and semiarid regions in China and Mongolia and transported downwind over thousands of kilometers, potentially affecting various ecosystems [18]. The most intense dust outbreaks occur in the spring season coinciding with the vegetation growing season that further amplifies the importance of dust in dryland ecosystems.

Assessment of PAR along with SW and LW components of the surface energy balance in dust-laden conditions necessitates a consistent representation of the dust optical characteristics across the wide spectral range (i.e., from the UV to the IR). Current measurement capabilities cannot provide this information so that optical modeling must be performed to compute the required spectral optical characteristics. However, computation of the optical characteristics, such as extinction coefficient, single scattering albedo, and scattering phase function, is subject to large uncertainties due to the complex nature of mineral aerosols. Dust particles exhibit various nonspherical shapes, mineralogical compositions, and size spectra that depend on dust sources and physicochemical changes (aging) of dust particles during the transport in the atmosphere [19]. To perform optical modeling for radiative budget assessments, past studies often considered dust as a single generic species and used a spectral refractive index reported for limited dust bulk samples collected in a few geographical regions. For instance, the dust refractive index used by Yoshioka et al. [20] was a combination of data from Patterson [21] for the visible spectrum, from Sokolik et al. [22] for the near-infrared (near-IR), and from Volz [23] for the IR, despite the fact that these datasets represent three completely different dust samples-one from Central Asia and the other two from Northern Africa. The OPAC (Optical Properties of Aerosols and Clouds) library, which is widely used in the radiation/climate modeling, also consists of the bulk dust models that are based on the Patterson and Volz refractive indices [24]. To overcome these limitations, here we explicitly consider the size-resolved mineralogical composition of dust aerosol that allows the use of the spectral refractive indices of the major minerals $[2,25,26]$. One key advantage of this approach is that it is possible to incorporate recent data of dust mineralogical composition, providing the improved representation of region-specific dust optical characteristics from the UV to the IR.

The radiative impact of aerosols also depends on the properties and state of the underlying land surfaces that control surface albedo and emissivity. In dryland regions, surface albedo exhibits large spatiotemporal and spectral variability. In particular in the case of barren and sparsely vegetated surfaces, albedo depends on a combination of several factors such as soil type, composition, and moisture [27,28]. For vegetated surfaces, the variability of the surface albedo is controlled by the plant phenology [29]. Shrublands and grasslands exhibit the largest albedo variations in space and time compared to other land categories [29]. Although surface albedo varies with wavelength, it is commonly represented in regional and global climate models by a wavelength-independent constant (often called SW broadband albedo), which is then prescribed to a certain land category as part of the land surface module. Studies demonstrated that, however, neglecting the spectral dependence of surface albedo (e.g., in the visible versus near-IR) can lead to significant errors in modeled climate variables [30]. Therefore, it is important to account for the spectral surface albedo and its spatiotemporal variability to better understand the regional and temporal (e.g., seasonal) dynamics of the dust radiative impact.

The goal of this study is to assess the extent to which Asian dust can impact the PAR and surface radiative energy balance considering the regional specifics of Asian dust properties and spectral surface albedo in the dryland ecosystems of East Asia. The specific objectives are to (1) compute and examine the size- and composition-dependent spectral (i.e., from the UV to the IR) behavior of Asian dust optical characteristics, (2) determine the spectral surface albedo of 
the major dryland ecosystems in East Asia that are frequently affected by dust transport, (3) examine the dust radiative impact on the total PAR, diffuse fraction of PAR, and surface energy balance in these ecosystems, and (4) explore implications of the dust radiative impact on the ecosystem functioning using several light use efficiency models. Our approach is to perform a comprehensive one-dimensional radiative transfer modeling constrained by ground-based and satellite observations of dust aerosol and land surface properties.

The paper is organized as follows. Section 2 introduces the data and methodology used in this study. Analysis of computed dust spectral optical properties is presented in Section 3. This section also presents our results of the dust impact on the PAR and surface radiative balance in different dryland ecosystems and assessments of associated changes in the ecosystem LUE and photosynthetic rates. Section 4 summarizes our major findings and addresses the implications.

\section{Methodology and Data}

We used a one-dimensional radiative transfer code SBDART (Santa Barbara DISORT Atmospheric Radiative Transfer, [31]) to compute radiative fluxes. SBDART solves the radiative transfer equation in a vertically inhomogeneous planeparallel atmosphere taking into account scattering, absorption, and emission by major gases and aerosols. The SBDART code was modified to allow for the incorporation of a new module to treat the aerosol vertical profile and spectral dust optical characteristics that were computed in this study (see Section 3.1). In addition, spectral surface albedos were reconstructed for the dominant dryland ecosystems in East Asia (see Section 2.2) and incorporated into SBDART. Radiative transfer calculations were performed for cloud-free conditions with a spectral resolution of $0.05 \mu \mathrm{m}$ in the SW and $20 \mathrm{~cm}^{-1}$ in the LW. Spectral radiative fluxes were integrated over the certain wavelength intervals to calculate SW, LW, and PAR fluxes at the surface. We also computed and analyzed the diffuse component of PAR ( $\left.\mathrm{PAR}_{\text {dif }}\right)$, the diffuse fraction $(\alpha)$ of PAR, and the surface radiative balance (SRB) as follows:

$$
\begin{gathered}
\mathrm{PAR}_{\mathrm{dif}}=\mathrm{PAR}-\mathrm{PAR}_{\mathrm{dir}}, \\
\alpha=\frac{\mathrm{PAR}_{\mathrm{dif}}}{\mathrm{PAR}}, \\
\mathrm{SRB}=\left(\mathrm{SW}_{\mathrm{dn}}-\mathrm{SW}_{\mathrm{up}}\right)+\left(\mathrm{LW}_{\mathrm{dn}}-\mathrm{LW}_{\mathrm{up}}\right),
\end{gathered}
$$

where $\mathrm{SW}_{\mathrm{dn}}, \mathrm{SW}_{\mathrm{up}}, \mathrm{LW}_{\mathrm{dn}}$, and $\mathrm{LW}_{\mathrm{up}}$ denote the surface downwelling SW flux, upwelling SW flux, downwelling LW flux, and upwelling LW flux, respectively. Here, PAR is the total photosynthetically active radiation incident at the surface and $\mathrm{PAR}_{\text {dir }}$ is its direct component.

We also computed and analyzed the efficiency of dust radiative forcing in the PAR $\left(\delta_{\mathrm{PAR}}\right)$ and in the surface radiative balance $\left(\delta_{\mathrm{SRB}}\right)$ defined as the differential change in these quantities per change in the dust aerosol optical depth at $0.5 \mu \mathrm{m}, \tau_{0.5}$ :

$$
\begin{aligned}
& \delta_{\mathrm{PAR}}=\frac{d \mathrm{RF}_{\mathrm{PAR}}}{d \tau_{0.5}}, \\
& \delta_{\mathrm{SRB}}=\frac{d \mathrm{RF}_{\mathrm{SRB}}}{d \tau_{0.5}},
\end{aligned}
$$

where $\mathrm{RF}_{\mathrm{PAR}}$ is the radiative forcing in PAR, $\mathrm{RF}_{\mathrm{PAR}}=\mathrm{PAR}_{\text {dust }}-$ $\mathrm{PAR}_{\text {clean }}$, and $\mathrm{RF}_{\mathrm{SRB}}$ in the radiative forcing in the surface radiative balance, $\mathrm{RF}_{\mathrm{SRB}}=\mathrm{SRB}_{\text {dust }}-\mathrm{SRB}_{\text {clean }}$. Here, the subscript "clean" denotes clean (aerosol-free) atmospheric condition.

\subsection{Selection of Mineralogical Composition and Particle Size} Distributions Representative of Asian Dust. We used a Mie code to compute the dust optical characteristics over the wide spectral range (from the UV to thermal IR) that is required for this study. As a necessity, dust particles are assumed to be spheres. A number of studies have demonstrated the validity of the spherical shape assumption in radiative flux calculations. For instance, Fu et al. [32] showed that this assumption caused less than 5\% error in radiative fluxes compared to the spheroidal-shape approximation. Yi et al. [33] reported the $5-10 \%$ error in surface radiative fluxes over land by comparing the results for spheres versus ellipsoids.

The dust composition is represented by a mixture of quartz, calcite, and clay-iron oxide aggregates based on recent measurements of the size-resolved mineralogical composition of Asian dust [25, 26]. Quartz and calcite both have negligible absorption in the SW but exhibit significant absorption in the LW [2]. Clays are often aggregated with iron oxides in such a way that these aggregates have much higher light absorption than individual minerals. In particular, illite is found to be the most abundant type of clay in Asian dust, while goethite and hematite are two most important iron oxides [25]. The clay-iron oxide aggregates considered in our modeling are illite-hematite (IH) and illite-goethite (IG) following Lafon et al. [25]. The effective refractive indices of the aggregates were computed using the Bruggeman approximation [2].

Past studies show that mineralogical composition varies with particle size. We used measurements reported by Lafon et al. [25] to constrain the composition of fine and coarse particle size modes. The number fractions of quartz, calcite, and iron oxide-clay aggregates in the fine mode are $16 \%$, $25 \%$, and $59 \%$, respectively, and they are $28 \%, 29 \%$, and $43 \%$ in the coarse mode. In both size modes, IG is assumed to constitute $70 \%$ of the aggregates (IG plus IH). An important factor that can significantly affect the light absorption by dust is the volume fraction $(\nu)$ of iron oxides (in this case hematite or goethite) in the aggregates. Here, we use the values representative of Asian dust as recommended by Lafon et al. [25], with $v$ being equal to $3.0 \%$ and $6.7 \%$ for the fine and coarse modes, respectively.

Selection of representative dust particle size distributions was performed by examining measurements from several AERONET sites located in East Asia, including Dunhuang, Inner Mongolia, Yulin, and Beijing. These sites are located 


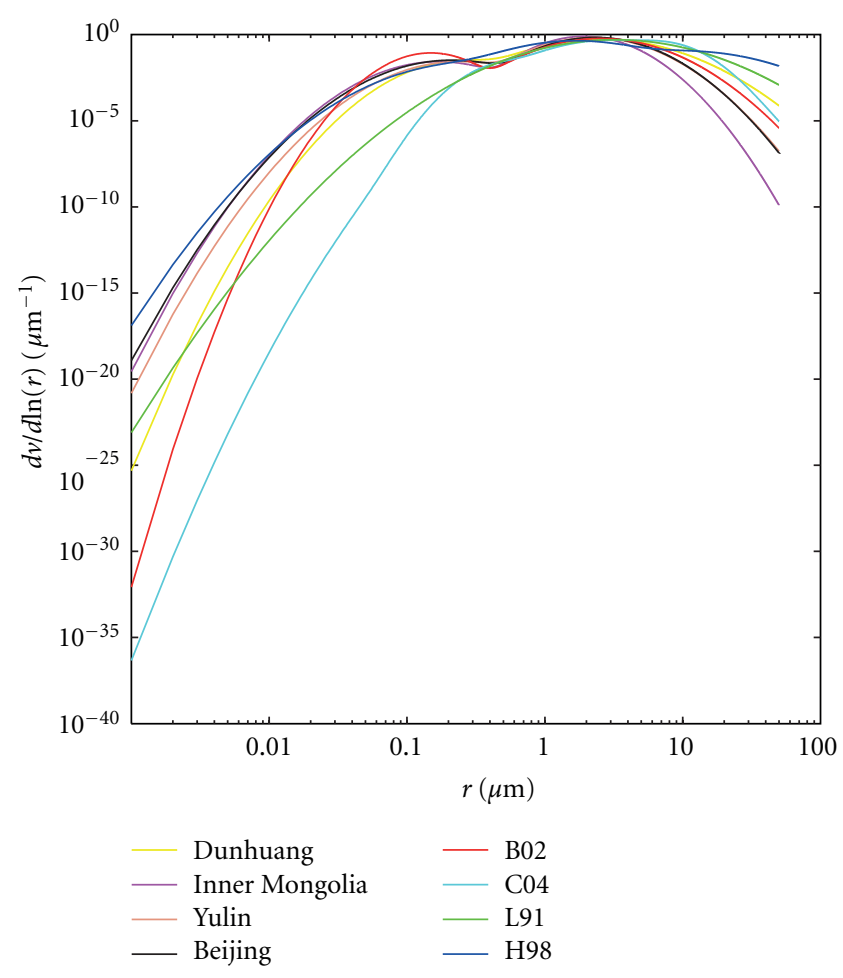

Figure 1: Normalized dust volume size distributions for the dust cases considered in this study (see text for details). The associated size distribution parameters are given in Table 1.

along the transport routes of dust originating from the Taklamakan and Gobi deserts. Because these stations are located at different distances from the dust sources, selected aerosol size distributions help to examine how dust optical properties can change during transport and implications to the dust radiative impact.

AERONET size distributions are retrieved from measurements of the sun and sky radiances and reported in terms of the standard parameters of a bimodal lognormal function including the volume median radius and geometric standard deviation [36]. AERONET also measures the aerosol optical depth $(\tau)$ at several wavelengths. These measurements are used to derive the Ångström exponent $(\beta)$. Given that dust events are commonly associated with relatively large aerosol optical depth and the presence of coarse particles, we selected several representative dust size distribution cases by examining daily averaged $\tau_{0.5}$ and the Ångström exponent during spring 2001, when the AERONET sites in East Asia provided intensive observations as part of the ACE-Asia field campaign [18]. The $\beta$ is inversely related to particle size such that $\beta<0.5-0.7$ is often used to identify dust events.

For the considered time period, we found that the AERONET sites frequently showed high $\tau_{0.5}$ and low $\beta$, and the retrieved size distributions contained large amounts of coarse particles. The relative proportion of the fine and coarse modes, however, showed significant temporal variations at all sites. To address this observed dynamics in aerosol size spectra, for our modeling we selected four representative cases shown in Table 1. In addition, we considered four dust
TABle 1: Parameters of dust volume size distributions from AERONET sites in East Asia (Dunhuang, Inner Mongolia, Yulin, and Beijing) and past studies. The lognormal parameters shown are volume median radius $(\mu \mathrm{m})$, geometric standard deviation, and mass fraction (\%).

\begin{tabular}{|c|c|c|c|c|}
\hline Size Distribution & Source & \multicolumn{2}{|c|}{ Fine mode(s) } & $\begin{array}{l}\text { Coarse } \\
\text { mode }\end{array}$ \\
\hline \multirow{3}{*}{ Dunhuang } & \multirow{3}{*}{ AERONET } & \multicolumn{2}{|c|}{$0.254 \mu \mathrm{m}$} & $2.561 \mu \mathrm{m}$ \\
\hline & & \multicolumn{2}{|c|}{1.697} & 2.024 \\
\hline & & \multicolumn{2}{|c|}{$4.0 \%$} & $96.0 \%$ \\
\hline \multirow{3}{*}{ Inner Mongolia } & \multirow{3}{*}{ AERONET } & \multicolumn{2}{|c|}{$0.169 \mu \mathrm{m}$} & $1.932 \mu \mathrm{m}$ \\
\hline & & \multicolumn{2}{|c|}{1.757} & 1.623 \\
\hline & & \multicolumn{2}{|c|}{$3.8 \%$} & $96.2 \%$ \\
\hline \multirow{3}{*}{ Yulin } & \multirow{3}{*}{ AERONET } & \multicolumn{2}{|c|}{$0.235 \mu \mathrm{m}$} & $2.23 \mu \mathrm{m}$ \\
\hline & & \multicolumn{2}{|c|}{1.786} & 1.758 \\
\hline & & \multicolumn{2}{|c|}{$3.9 \%$} & $96.1 \%$ \\
\hline \multirow{3}{*}{ Beijing } & \multirow{3}{*}{ AERONET } & \multicolumn{2}{|c|}{$0.209 \mu \mathrm{m}$} & $2.331 \mu \mathrm{m}$ \\
\hline & & \multicolumn{2}{|c|}{1.815} & 1.736 \\
\hline & & \multicolumn{2}{|c|}{$4.9 \%$} & $95.1 \%$ \\
\hline \multirow{3}{*}{ B02 } & \multirow{3}{*}[36]{} & \multicolumn{2}{|c|}{$0.149 \mu \mathrm{m}$} & $2.538 \mu \mathrm{m}$ \\
\hline & & \multicolumn{2}{|c|}{1.52} & 1.84 \\
\hline & & \multicolumn{2}{|c|}{$9.1 \%$} & $90.9 \%$ \\
\hline \multirow{3}{*}{ C04 } & \multirow{3}{*}[37]{} & $0.53 \mu \mathrm{m}$ & $2.751 \mu \mathrm{m}$ & $7.099 \mu \mathrm{m}$ \\
\hline & & 1.46 & 1.85 & 1.50 \\
\hline & & $1.8 \%$ & $69.4 \%$ & $28.8 \%$ \\
\hline \multirow{3}{*}{ L91 } & \multicolumn{4}{|c|}{$3.228 \mu \mathrm{m}$} \\
\hline & \multicolumn{4}{|c|}{2.20} \\
\hline & \multicolumn{4}{|c|}{$100 \%$} \\
\hline \multirow{3}{*}{ H98 } & \multirow{3}{*}[24]{} & $0.267 \mu \mathrm{m}$ & $1.648 \mu \mathrm{m}$ & $11.02 \mu \mathrm{m}$ \\
\hline & & 1.95 & 2.00 & 2.15 \\
\hline & & $3.4 \%$ & $76.1 \%$ & $20.5 \%$ \\
\hline
\end{tabular}

size distributions from past studies. B02 denotes the size distribution averaged from 8-year AERONET data at the Bahrain site, which was suggested as a representative size distribution of dust aerosol [36]. C04 was measured by Clarke et al. [37] during the ACE-Asia campaign on a strong dust event. L91 is the single-mode particle size distribution of d'Almeida [38], which is included in the OPAC library [24]. L91 is thought to represent the long-range transported dust. We also considered another dust size distribution from OPAC consisting of three size modes (hereafter H98). Table 1 presents all the considered size distributions in terms of their parameters of the lognormal size distribution expressed as

$$
\frac{d V(r)}{d(\log r)}=\sum_{j} \frac{V_{j}}{\sqrt{2 \pi} \log \sigma_{j}} \exp \frac{\left(\log r-\log r_{0 v, j}\right)^{2}}{2\left(\log \sigma_{j}\right)^{2}},
$$

where $j$ denotes the $j$ th size mode with the volume concentration $\left(V_{j}\right)$, volume median radius $\left(r_{0 v, j}\right)$, and geometric standard deviation $\left(\sigma_{j}\right)$.

These size distributions are further compared in Figure 1. Various similarities and differences are apparent. Some 


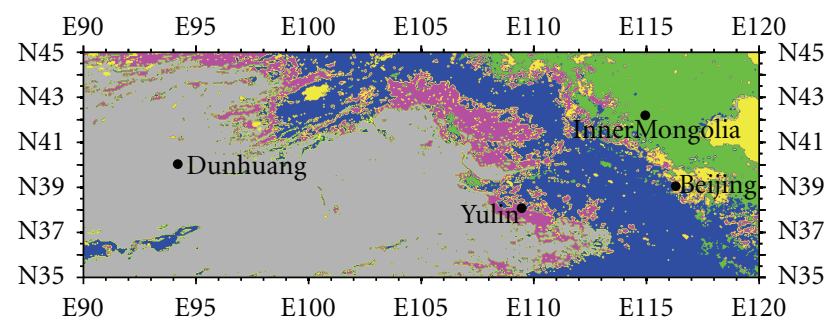

(a)

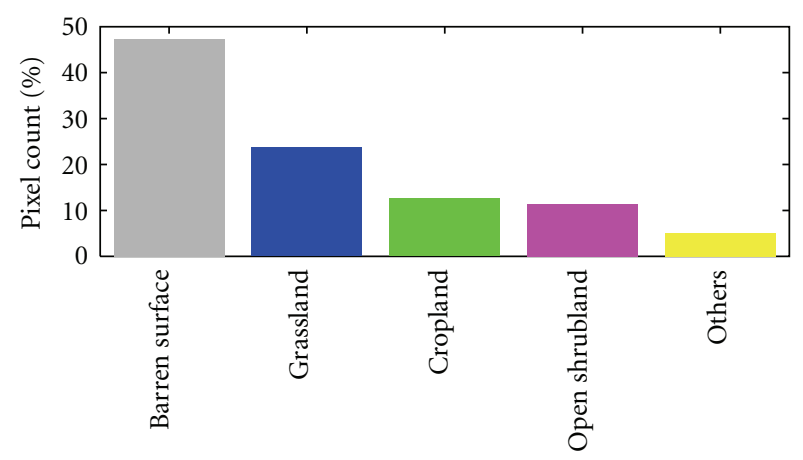

(b)

FIgure 2: (a) MODIS land cover map of the study domain. The locations of four AERONET sites (Dunhuang, Inner Mongolia, Yulin, and Beijing) are also shown. (b) Dominant ecosystem types identified from MODIS land cover statistics: barren surface, cropland, grassland, and open shrubland.

differences in measured size distributions could be due to the variability in size spectra controlled by the dust emission and transport processes, sedimentation of large particles, and mixing of dust with other types of aerosols. For example, at the Beijing site, dust aerosol can be mixed with fine particles originating from urban and industrial sources, so that the size distribution has a larger fine mode than at other sites (see Table 1). B02 has a larger fine mode than the size distributions from the Asian AERONET sites. This might be due to the multiyear averaging or because of an actual difference in dust sizes between Persian Gulf and East Asia. In addition, considered size distributions were derived by different means, either from the limited sampling at local sources, such as C04 and OPAC, or from column-averaged optical inversion, such as AERONET.

We first computed the spectral optical characteristics of each mineral species in each size mode of a certain size distribution, including the normalized extinction $K_{\mathrm{ext}, i, j}^{*}(\lambda)$ and scattering $K_{\mathrm{sc}, i, j}^{*}(\lambda)$ coefficients and asymmetry parameter $g_{i, j}$, where $i$ denotes the $i$ th mineral species and $j$ denotes the $j$ th size mode. Then, for the $j$ th mode, the normalized extinction coefficient is calculated by summing up the normalized extinction coefficient of each species weighted by its number fraction, $f_{i, j}$ :

$$
K_{\text {ext }, j}^{*}(\lambda)=\sum f_{i, j} K_{\text {ext, }, i j}^{*}(\lambda) .
$$

For instance for the fine mode, (6) is

$$
K_{\mathrm{ext}, f}^{*}=f_{\mathrm{cal}, f} K_{\mathrm{cal}, f}^{*}+f_{\mathrm{qtz}, f} K_{\mathrm{qt}, f}^{*}+f_{\mathrm{IG}, f} K_{\mathrm{IG}, f}^{*}+f_{\mathrm{IH}, f} K_{\mathrm{IH}, f}^{*},
$$

where the subscripts cal, qtz, IG, and IH denote calcite, quartz, IG aggregate, and IH aggregate, respectively. $K_{\mathrm{ext}, j}^{*}(\lambda)$ $\left(\mathrm{km}^{-1} / \mathrm{cm}^{-3}\right)$ is then weighted by the number concentration $N_{j}$ of each mode to give the extinction coefficient of the dust mixture:

$$
K_{\text {ext }}(\lambda)=\sum N_{j} K_{\text {ext }, j}^{*}(\lambda) .
$$

The $K_{\text {ext }}(\lambda)$ can also be expressed in terms of the particle mass concentration. The $N_{j}$ is related to the total mass concentration $(M)$ as $N_{j}=m_{j} M / M_{j}^{*}$. Here $m_{j}$ is the mass fraction of the $j$ th mode and $M_{j}^{*}=$ $4 / 3 \pi \rho r_{0 v, j}^{3} \exp \left(-9\left(\log \sigma_{j}\right)^{2} / 2\right)\left(\mu \mathrm{g} \mathrm{m}^{-3} / \mathrm{cm}^{-3}\right)$, where $r_{0 v, j}$ is the volume median radius (see (5)) and $\rho$ is the particle density (in our case, $2.5 \mathrm{~g} \mathrm{~cm}^{-3}$ ). The scattering coefficient $K_{\mathrm{sc}}(\lambda)$ can be calculated in a similar fashion, so the single scattering albedo $\omega_{0}$ of the dust mixture is

$$
\omega_{0}(\lambda)=\frac{K_{\mathrm{sc}}(\lambda)}{K_{\mathrm{ext}}(\lambda)} .
$$

By performing the Mie calculations for the selected dust size distributions (shown in Table 1) and comparing the results to the aerosol optical depth measured at AERONET sites, we selected $M=250,500$, and $750 \mu \mathrm{g} \mathrm{m}^{-3}$ to represent low, moderate, and high dust loadings, respectively.

The computed spectral optical characteristics of Asian dust were then incorporated into the SBDART code. The dust vertical profile was specified based on the CALIPSO (CloudAerosol Lidar and Infrared Pathfinder Satellite Observations) lidar data. We examined the CALIPSO vertical feature mask during spring 2007 in East Asia to select the representative cases. We found that Asian dust aerosol often extends from the ground up to $4 \mathrm{~km}$ in the dust source regions and downwind, although dust layers aloft reaching up to 8 or $9 \mathrm{~km}$ were also observed. Here we consider two different profiles: one with a uniform dust layer between 0 and $4 \mathrm{~km}$, (hereafter the mixed layer) and another one with an elevated layer between 5 and $9 \mathrm{~km}$ (hereafter the elevated layer).

2.2. Reconstruction of Spectral Surface Albedo. We used the MODIS land products to obtain the spectral surface albedo for the dryland ecosystems that are affected by the dust in East Asia. We first examined the MODIS (Moderate Resolution Imaging Spectroradiometer) CMG (Climate Modeling Grid) land cover product (MOD12C1), which contains fractions of each IGBP (International Geosphere-Biosphere Program) land type in $1 \mathrm{~km}$ resolution pixels. These fractions are used to identify pure ( $>95 \%$ coverage) land cover grids for each land type. Figure 2(a) shows a land cover map of the region $\left(\mathrm{N} 35^{\circ}-\mathrm{N} 45^{\circ}, \mathrm{E} 90^{\circ}-\mathrm{E} 120^{\circ}\right)$ for which we identified four dominant land types: barren surface, cropland, grassland, and open shrubland (see Figure 2(b)).

To assign the albedo to different ecosystems, the land cover is collocated with the MODIS CMG albedo (MCD43C) 


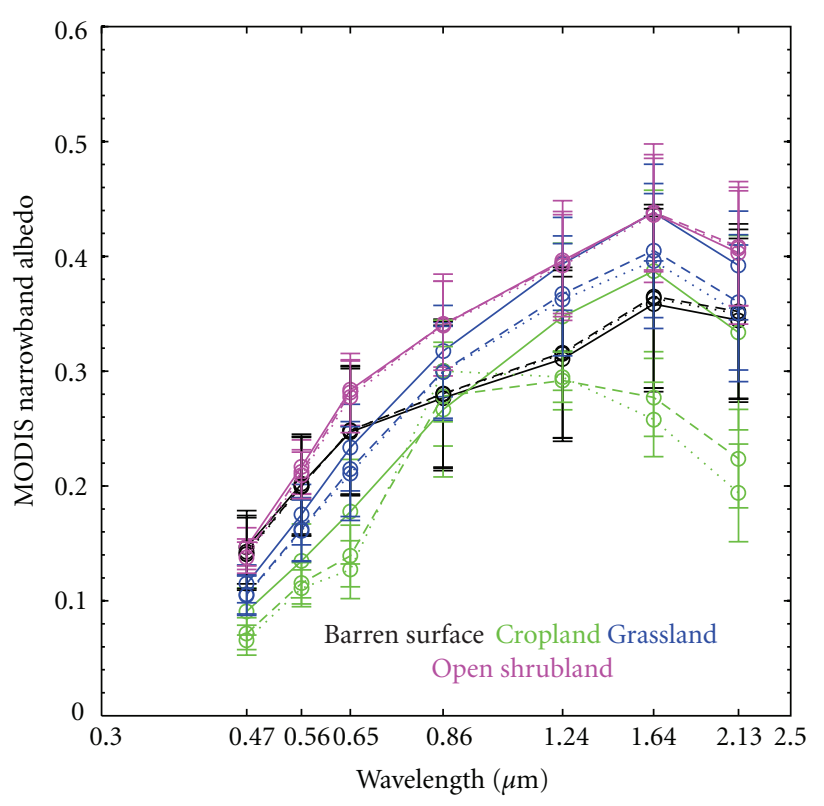

(a)

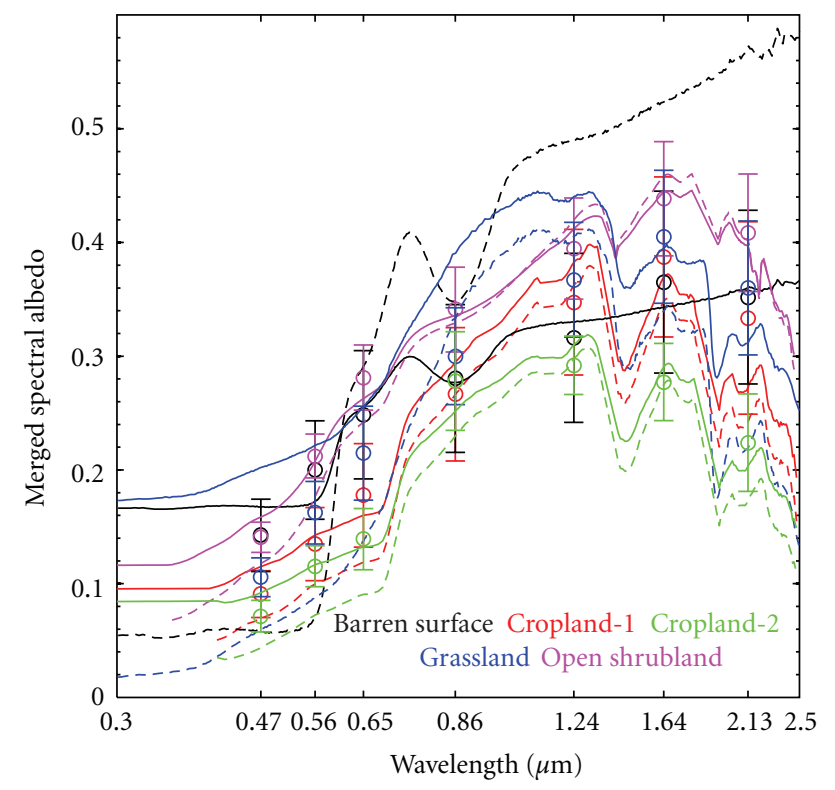

(b)

Figure 3: (a) Mean value (unfilled circles) and standard deviation (error bars) of MODIS narrowband albedo for different dryland ecosystems (barren surface, cropland, grassland, and open shrubland). Data are averaged for the production periods of April 23 (solid curve), May 1 (dash curve), and May 9 (dotted curve) in 2001. (b) Reconstructed spectral surface albedo (solid curves) by merging MODIS albedo with the USGS spectroscopy dataset (dotted curves).

data. The MODIS CMG albedo is generated every 8 days on a geographic latitude/longitude projection at 0.05 degree resolution [29]. The CMG albedo is reported at seven narrowbands centered at $0.47,0.56,0.65,0.86,1.24,1.64$, and $2.13 \mu \mathrm{m}$. It consists of white-sky albedo and black-sky albedo that represent contributions from the diffuse and direct solar radiation components, respectively. The white-sky albedo is used in our calculations in accordance with the Lambertian surface assumption in SBDART. Pixels with best retrieval quality were selected to compute a spatial mean value and standard deviation of the surface albedo during the growth season (April 23-31, May 1-8, and May 9-17 in 2001). Figure 3(a) shows that albedo values of barren surface and open shrubland change little with time. The cropland albedo exhibits the largest temporal variability due to the vegetation phenology and land management. This is consistent with previous findings by Gao et al. [29]. For our analyses, we selected five cases of the surface albedo: cropland (hereafter cropland-1) for April 23-31, and barren surface, grassland, open shrubland, and cropland (hereafter cropland-2) for May 1-8.

To provide the detailed spectral dependence of surface albedo, we merged the MODIS narrowband albedo with the USGS spectroscopy dataset. The USGS spectroscopy library (http://speclab.cr.usgs.gov/spectral.lib06/ds231/datatable .html) provides detailed wavelength dependence of albedo for various land targets. This allows expansion of the MODIS narrowband albedo across the entire solar spectrum. To do so, we matched MODIS land types with corresponding land targets from the spectroscopy dataset. Then, we selected the spectroscopy data that best relate to MODIS albedo in the seven narrowbands and applied a least-square fitting to calculate values of the corresponding spectral surface albedo. The resulting spectral surface albedos serve as input into SBDART and are shown in Figure 3(b). These albedos capture the spectral behavior of MODIS narrowband albedo and contain the detailed spectral information from the USGS spectroscopy dataset.

\section{Results}

3.1. Examination of Spectral Optical Characteristics of Asian Dust. Using the size distributions presented in Table 1, we computed the dust spectral optical characteristics from the UV to the IR. Figures 4(a) and 4(b) show the extinction coefficient $\left(K_{\text {ext }}\right)$ for the dust loading $M=250 \mu \mathrm{g} \mathrm{m}^{-3}$ and the single scattering albedo $\left(\omega_{0}\right)$ in the SW. For comparison, we also show the OPAC bulk dust optical characteristics (denoted by H98). All shown cases have the same composition, except the Inner Mongolia_agg dust and H98, so the strong influence of size distribution on the magnitude and spectral behavior of $K_{\text {ext }}$ and $\omega_{0}$ in the solar and IR (not shown) is apparent. The Inner Mongolia_agg dust has the same size distribution as Inner Mongolia (see Table 1) but consists only of clay-iron oxide aggregates. This case, associated with the largest light absorption compared to other Asian dust cases shown in Figure 4 helps to demonstrate the influence of the mineralogical composition on dust optics. This composition difference has little effect on $K_{\text {ext }}$, but it causes a significant decrease in $\omega_{0}$, for example, from 0.93 to 0.84 at $0.5 \mu \mathrm{m}$ with even larger decrease across the PAR region towards the shorter wavelength. Comparing to our Asian dust cases, the OPAC bulk dust model (H98) has relatively high $K_{\text {ext }}$ values but the lowest $\omega_{0}$. 


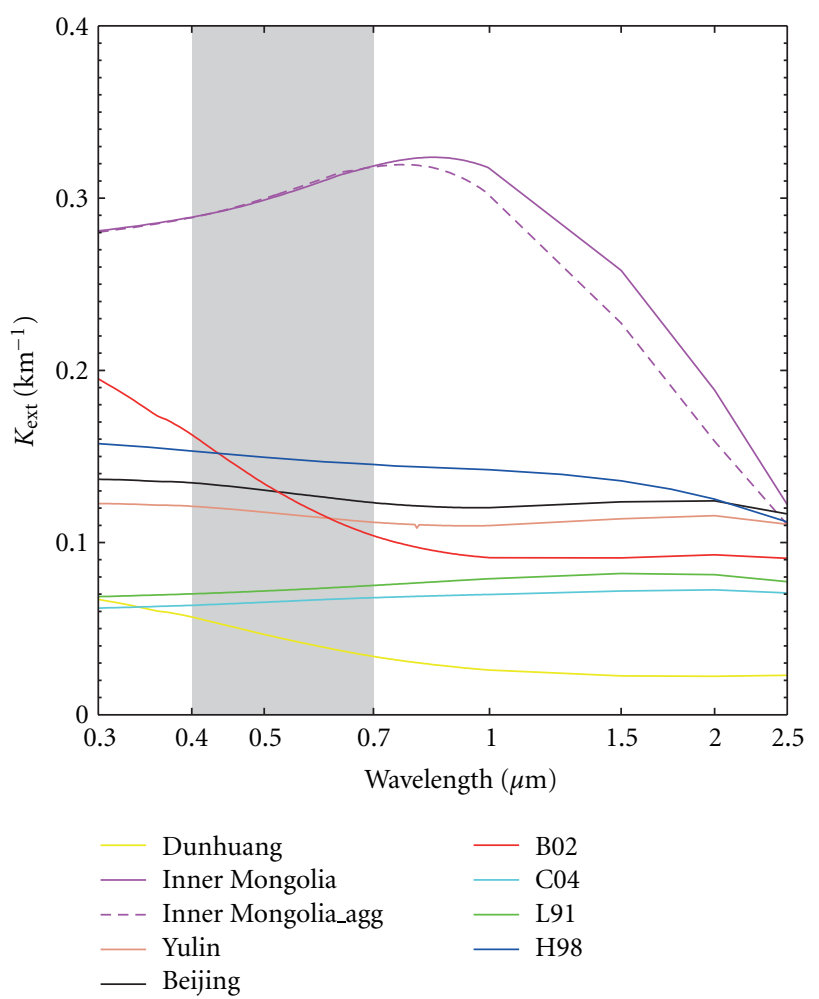

(a)

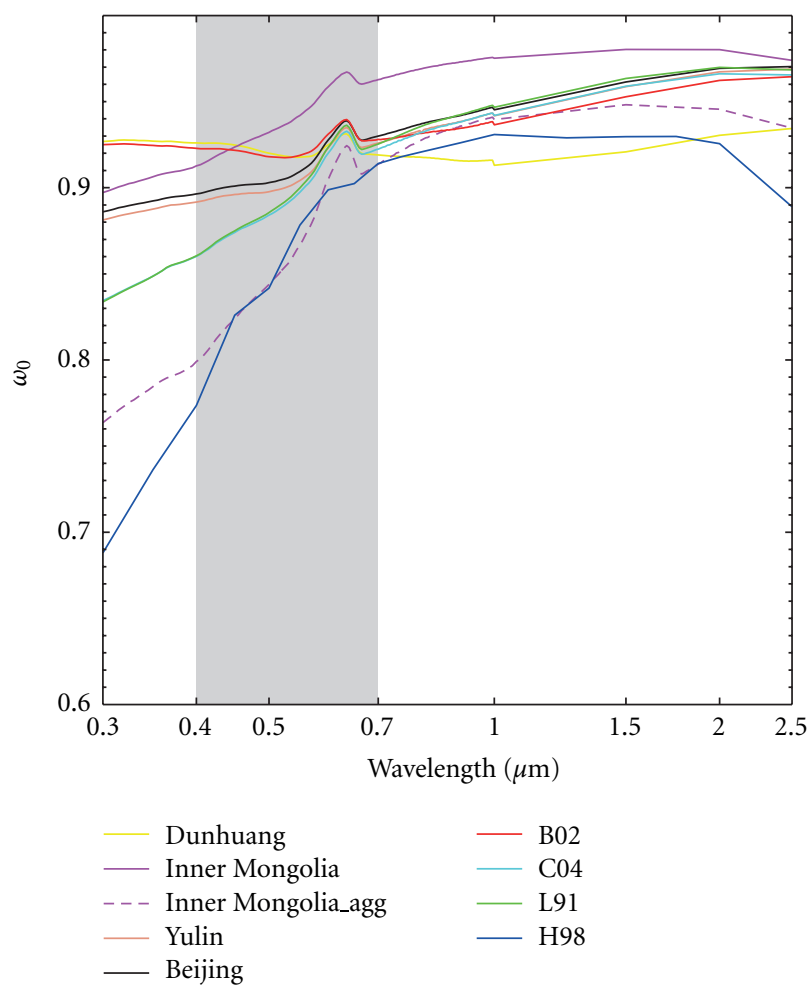

(b)

FIgURE 4: (a) Extinction coefficient $K_{\text {ext }}$ for dust loading $M=$ $250 \mu \mathrm{g} \mathrm{m}^{-3}$, and (b) single scattering albedo $\left(\omega_{0}\right)$ computed for Asian dust and OPAC bulk dust (H98) cases. Shaded areas highlight the PAR spectral region.
Even for the same composition, the dust $\omega_{0}$ strongly varies among the considered size distributions, for example, $\omega_{0}(0.5 \mu \mathrm{m})$ ranges from 0.88 to 0.93 . These values of $\omega_{0}$ $(0.5 \mu \mathrm{m})$ are comparable to those reported by past studies for Asian dust-laden environments: $0.88 \pm 0.07(0.55 \mu \mathrm{m})$ at an urban site in Seoul, Republic of Korea [39], $0.919 \pm 0.056$ at Gosan [40], $0.957 \pm 0.031(0.55 \mu \mathrm{m})$ from the in situ measurements during ACE-Asia [41], and $0.97 \pm 0.01(0.55 \mu \mathrm{m})$ from the aircraft measurements of an Asian dust plume over the Pacific [42].

The large spread of $K_{\text {ext }}$ values at $0.5 \mu \mathrm{m}$ is clearly seen in Figure 4(a). One important implication is that, for a given dust loading, this results in large differences in the aerosol optical depth, $\tau_{0.5}$. Figure 5 shows $\tau_{0.5}$ computed for three different dust loads for all dust cases shown in Figure 4(a). Significant differences seen in $\tau_{0.5}$ values suggest that caution must be exercised in interpreting linkages between $\tau_{0.5}$ and dust loading, which will be further addressed below.

In terms of the spectral behavior, $K_{\text {ext }}$ varies slightly with wavelength in the SW, except for the Dunhuang, Inner Mongolia, and B02 dust cases, which are associated with very small Ångström exponents. For the Inner Mongolia case, $K_{\text {ext }}$ increases with wavelength up to $0.8 \mu \mathrm{m}$ and rapidly decreases in the near-IR, while for Dunhuang and B02 cases, $K_{\text {ext }}$ decreases with wavelength up to $1.0 \mu \mathrm{m}$ and then levels off. The value of $\omega_{0}$ increases with wavelength in the PAR region, except for the Dunhuang and B02 cases. In the latter cases, $\omega_{0}$ slightly decreases with wavelength in the PAR region and then increases in the near-IR. The spike at $0.66 \mu \mathrm{m}$ is due to the imaginary part of the refractive index of goethite. Note that $\omega_{0}$ computed for considered Asian dust cases has spectral behavior similar to that of Saharan dust reported by Otto et al. [43] (see their Figure 6).

Overall, examination of Figure 4 clearly shows that both $K_{\text {ext }}$ and $\omega_{0}$ strongly depend on the presence of both fine and coarse modes. This finding is in agreement with past studies (e.g., [43]) and reinforces the need for taking into account the broad range of particle sizes and having realistic representation of the fine/coarse mode ratio.

3.2. Impact of Dust on Total and Diffuse PAR. To assess the extent to which dust can affect the total PAR and its partitioning into direct and diffuse components, we performed radiative transfer modeling considering different combinations of dust optical cases and dryland ecosystems. PAR is absorbed by green vegetation and converted to biomass through photosynthesis. In ecological and land surface models, PAR is a key factor controlling the biophysical processes that govern photosynthesis and stomatal regulation of water, energy, and biogeochemical cycles. Figure 6(a) shows how PAR varies with $\tau_{0.5}$ for the considered dust cases. In each case, results are shown for three $\tau_{0.5}$ values corresponding to dust loadings of 250,500 , and $750 \mu \mathrm{g} \mathrm{m}^{-3}$. These results are for the mixed layer dust profile and sun elevation angle of $90^{\circ}$.

Under clean (dust-free) conditions, PAR varies from 490.0 to $495.6 \mathrm{Wm}^{-2}$ among the analyzed ecosystems (surface albedos). Note that Figure 6(a) only shows the results for cropland-2 and grassland, which represent the lowest and 


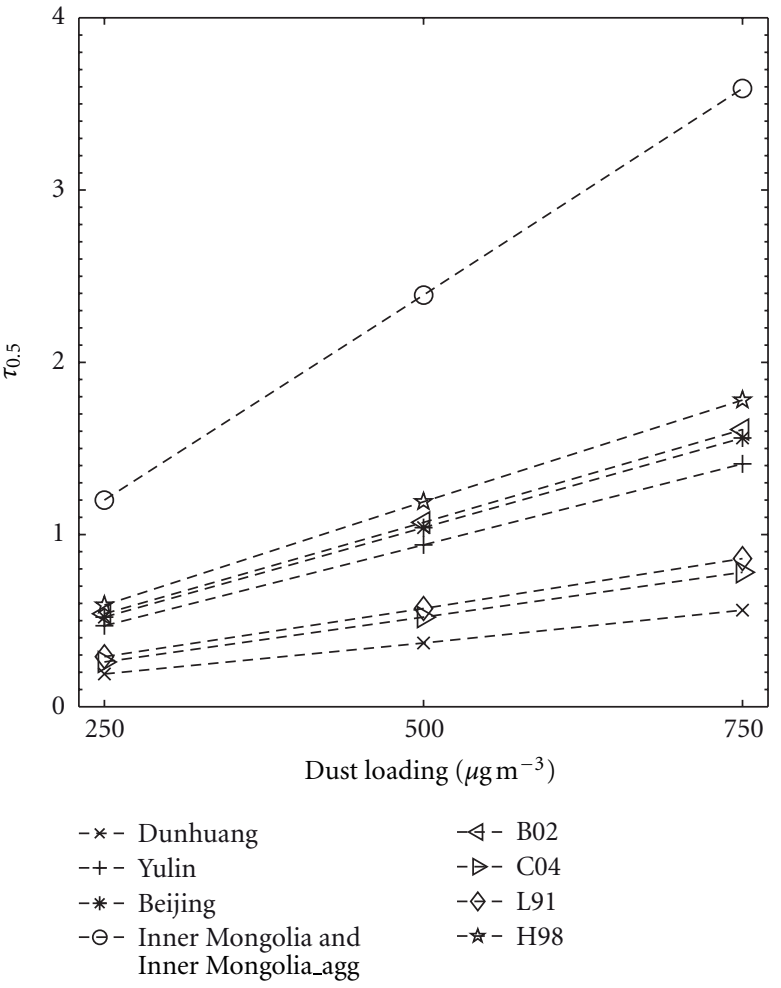

Figure 5: Dust optical depth at $0.5 \mu \mathrm{m}\left(\tau_{0.5}\right)$ computed for all dust cases at loadings of $M=250,500$, and $750 \mu \mathrm{g} \mathrm{m}^{-3}$.

highest values of surface albedo, respectively. For a given dust loading $M$, the case with the Inner Mongolia size distribution gives the highest $K_{\text {ext }}$ in the PAR region and hence the largest $\tau$, causing the largest reduction in PAR compared to other cases. The Dunhuang size distribution gives the lowest $K_{\text {ext }}$ values and hence the highest available PAR. For instance, for $M=250 \mu \mathrm{g} \mathrm{m}^{-3}$ and cropland-2 albedo, the reduction in PAR is $12.6 \mathrm{Wm}^{-2}$ for Dunhuang $\left(\tau_{0.5}=0.19\right)$ and $88.9 \mathrm{Wm}^{-2}$ for Inner Mongolia $\left(\tau_{0.5}=1.2\right)$, while the PAR reduction is $119.9 \mathrm{Wm}^{-2}$ for Inner Mongolia_agg. The latter indicates that the composition change alone contributes to a reduction in PAR of $31.0 \mathrm{Wm}^{-2}$. Due to its low $\omega_{0}$ values and relatively high $K_{\text {ext }}, \mathrm{H} 98$ dust causes a larger reduction in PAR than the other dust cases for the same loading, with the exception of the Inner Mongolia and Inner Mongolia_agg dust.

As seen in Figure 6(a), PAR is nearly linearly related to $\tau_{0.5}$ that supports the validity of using the dust forcing efficiency $\left(\delta_{\mathrm{PAR}}\right)$ (see $\left.(4)\right)$. The $\delta_{\mathrm{PAR}}$ mainly depends on the dust $\omega_{0}$ and to a lesser extent on the surface albedo. Computed $\delta_{\text {PAR }}$ values range from $-67.7 \mathrm{Wm}^{-2} \tau_{0.5}{ }^{-1}$ for the Inner Mongolia dust case to $-82.2 \mathrm{Wm}^{-2} \tau_{0.5}{ }^{-1}$ for the L91 case over cropland-2. The dust vertical profile is found to have a negligible effect on $\delta_{\text {PAR }}$.

Our modeling results are in good agreement with observations. In particular, we used radiation measurement data reported by Bush and Valero [44] in dust-laden conditions at Gosan, Republic of Korea, to compare with our modeling results. Based on their data, we estimated an efficiency $\delta_{\text {PAR }}$

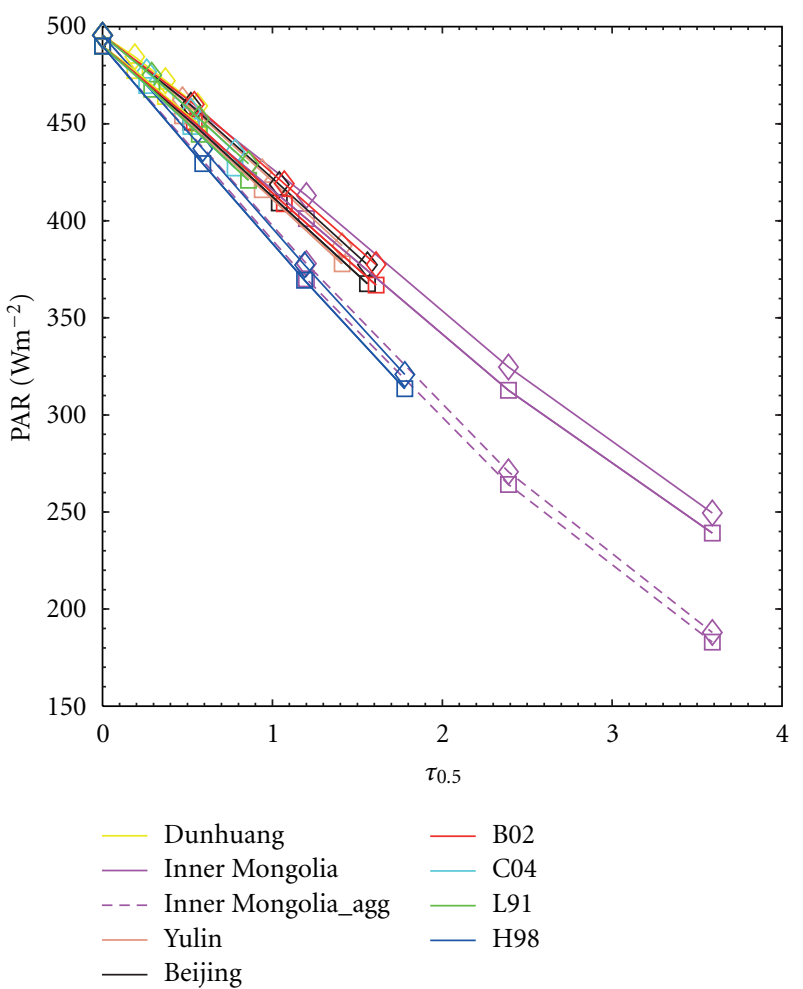

(a)

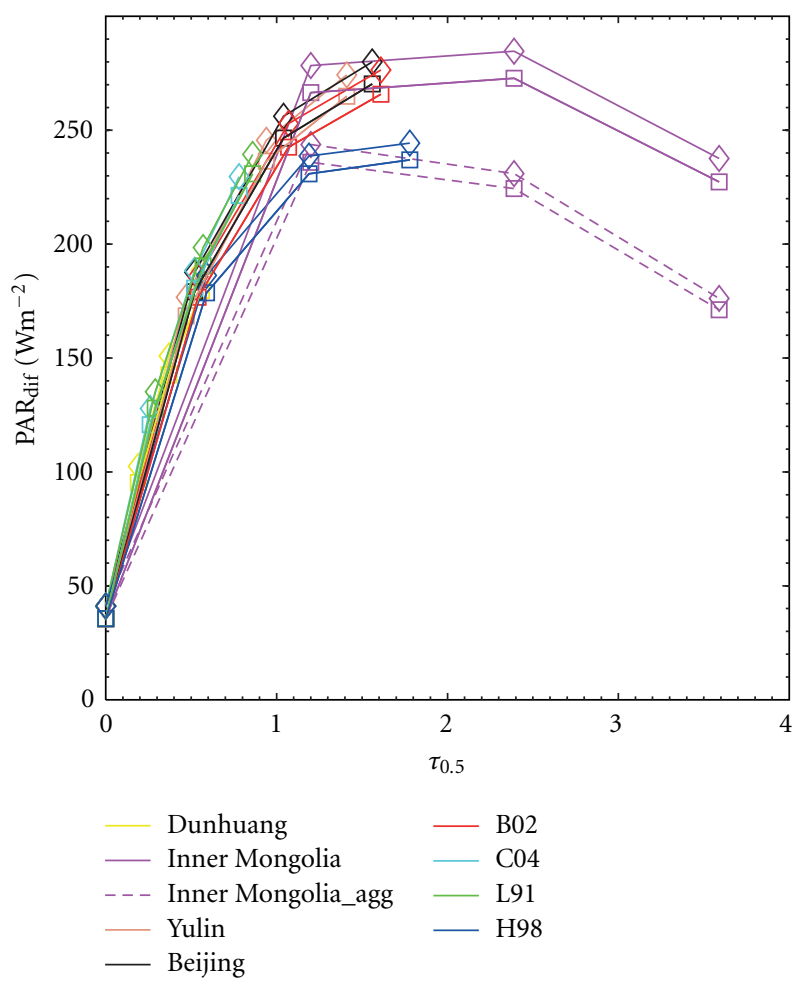

(b)

FIgURE 6: (a) Surface downwelling PAR as a function of dust optical depth $\left(\tau_{0.5}\right)$; (b) same as (a) but for the diffuse PAR component $\left(\mathrm{PAR}_{\mathrm{dif}}\right)$. Squares denote the use of cropland-2 surface albedo, and diamonds are for grassland. Sun elevation angle is $90^{\circ}$. Dust vertical profile is for mixed layer case. 


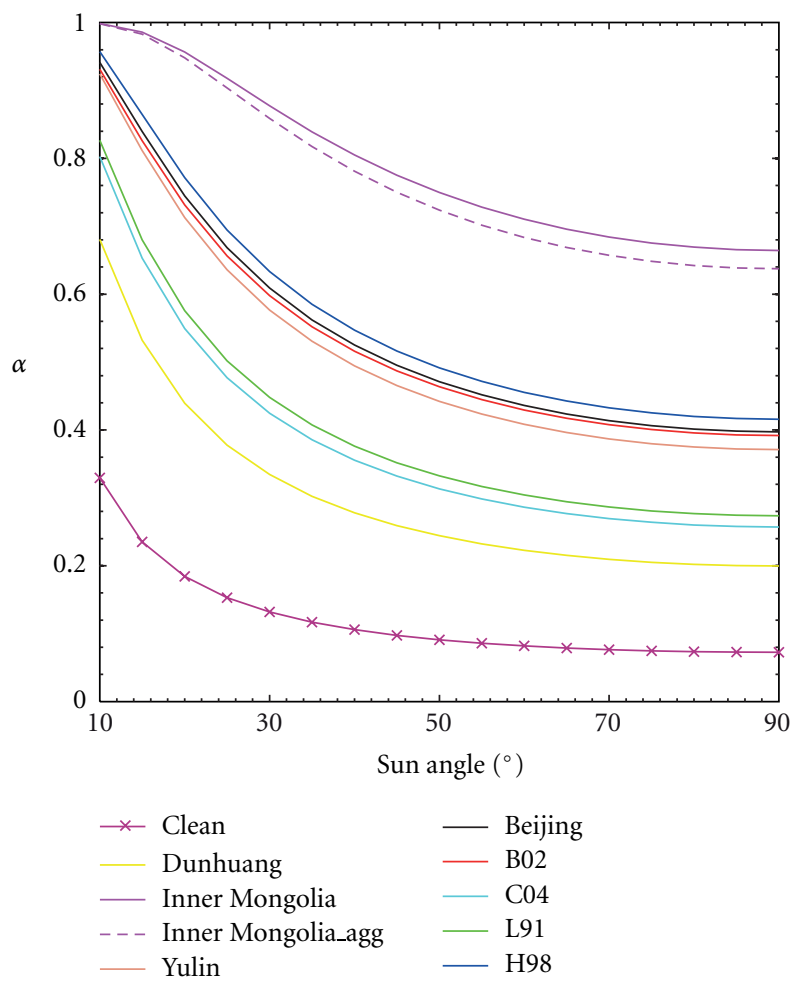

(a)

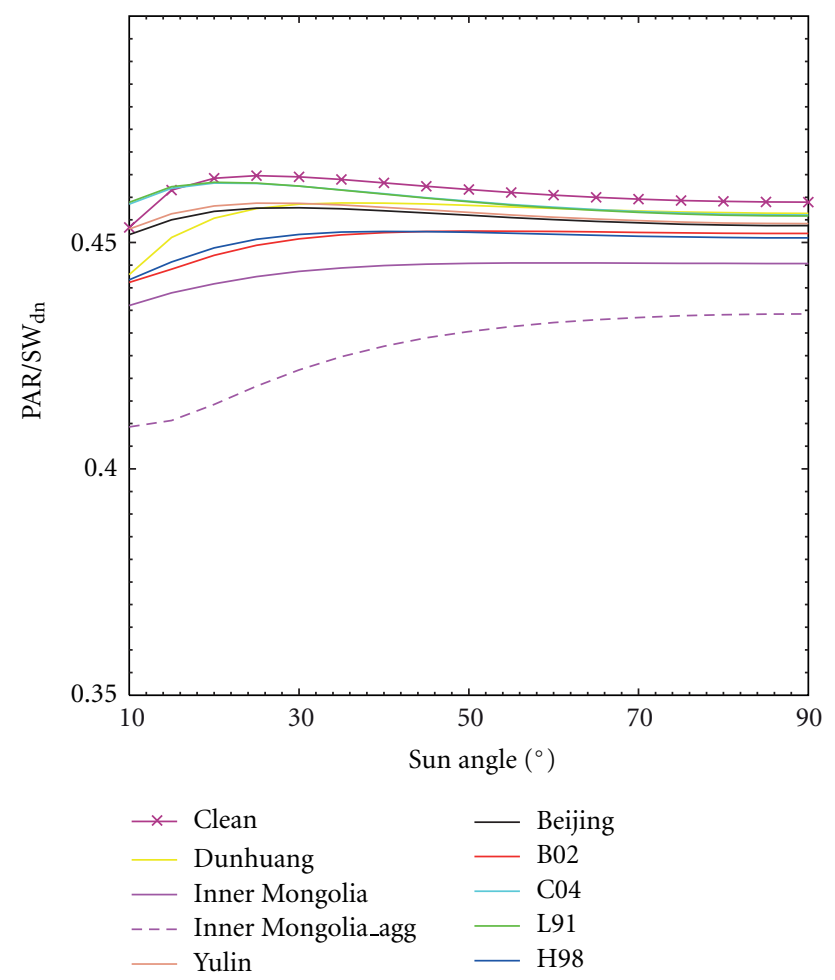

(b)

Figure 7: (a) Diffuse fraction $(\alpha)$ of PAR, and (b) the ratio of PAR to downwelling shortwave radiation, $\mathrm{PAR} / \mathrm{SW}_{\mathrm{dn}}$, as a function of sun elevation angle. Dust loading is $M=250 \mu \mathrm{g} \mathrm{m}^{-3}$. Dust vertical profile is for the mixed layer case. The surface albedo is for the cropland-2 case. of $-93.6 \pm 12.9 \mathrm{Wm}^{-2} \tau_{0.5}{ }^{-1}$. This value is slightly higher but in general agreement with our results.

As demonstrated in past studies, diffuse PAR $\left(\mathrm{PAR}_{\text {dif }}\right)$ is an important factor in assessing the plant gross photosynthetic rate due to the fact that $\mathrm{PAR}_{\mathrm{dif}}$ is often associated with higher light use efficiency than $\mathrm{PAR}_{\mathrm{dir}}$. Figure 6(b) shows that $\mathrm{PAR}_{\text {dif }}$ drastically increases in the presence of dust, although changes in $\mathrm{PAR}_{\text {dif }}$ differ between dust cases. For $M$ $=250 \mu \mathrm{g} \mathrm{m}^{-3}, \mathrm{PAR}_{\text {dif }}$ reaches $95.3 \mathrm{Wm}^{-2}$ for the Dunhuang case and $266.5 \mathrm{Wm}^{-2}$ for the Inner Mongolia case over cropland-2. These differences in $\mathrm{PAR}_{\text {dif }}$ changes are mainly due to the large difference in the dust optical depth between dust cases (see Figure 5). The compositional effect is seen by comparing the Inner Mongolia with Inner Mongolia_agg cases. The former causes $30.6 \mathrm{Wm}^{-2}$ more PAR $\mathrm{dif}_{\text {if }}$ than the latter due to the low $\omega_{0}$ associated with Inner Mongolia_agg case. Overall, $\mathrm{PAR}_{\text {dif }}$ tends to increase when $\mathrm{M}$ increases from 250 to $750 \mu \mathrm{g} \mathrm{m}^{-3}$, except for Inner Mongolia and Inner Mongolia_agg cases, for which $\mathrm{PAR}_{\text {dif }}$ begins to decrease when $\mathrm{M}$ increases from 500 to $750 \mu \mathrm{g} \mathrm{m}^{-3}$. When the dust profile was changed to the elevated-layer case, $\mathrm{PAR}_{\text {dif }}$ exhibited negligible changes.

The diurnal variation of aerosol loading and solar radiation can affect the ecosystem carbon uptake on a daily basis. To this end, we examined the solar angle dependence of the diffuse fraction of PAR ( $\alpha$, see (2)). Figure 7(a) shows that $\alpha$ remains low $(\sim 10 \%)$ during most of the day under dustfree conditions. Values of $\alpha$ become significantly higher in the presence of dust, especially at low sun elevation angles (measured as the angle above horizon). Here, we show the results for $M=250 \mu \mathrm{g} \mathrm{m}^{-3}$ and mixed layer dust profile. For all dust cases, $\alpha$ decreases with increasing sun angle before leveling off around $90^{\circ}$ (i.e., local noon). For a given dust loading, considered dust cases have very different optical depth values and, as a result, significant differences in $\alpha$ are clearly seen in Figure $7(\mathrm{a})$. For instance at $90^{\circ}, \alpha$ ranges from $20.0 \%$ for the Dunhuang case to $66.4 \%$ for the Inner Mongolia case. Due to solely the difference in $\omega_{0}, \alpha$ is reduced down to $63.7 \%$ for the Inner Mongolia_agg case compared to the Inner Mongolia case. We also found that $\alpha$ depends weakly (within $1.2 \%$ ) on the ecosystem type (i.e., surface albedo), but the sensitivity increases with dust loading due to the effect of multiple scattering.

Because of the lack of direct measurements of PAR, the common way to estimate its value is from measurements of downwelling SW radiation, $\mathrm{SW}_{\mathrm{dn}}$ [45]. In the models, PAR is often computed as a fraction of $\mathrm{SW}_{\mathrm{dn}}$. Although the PAR/ $\mathrm{SW}_{\mathrm{dn}}$ ratio remains fairly constant for a given location at daily or longer time scales, it is sensitive to the presence of clouds and aerosols [45]. Clouds generally increase the PAR/SW $\mathrm{dn}$ ratio due to the fact that clouds absorb much more in the near-IR than in the PAR spectrum. Aerosols can affect this ratio in a more complicated way, depending on the spectral dependence of the aerosol optical characteristics [45]. Figure 7 (b) shows that the $\mathrm{PAR} / \mathrm{SW}_{\mathrm{dn}}$ ratio remains nearly constant at $0.45( \pm 4 \%)$ for clean and dusty conditions, except for the Inner Mongolia_agg case. This is due to the fact that both the extinction coefficient and single scattering albedo of the Inner Mongolia_agg case have contrasting 


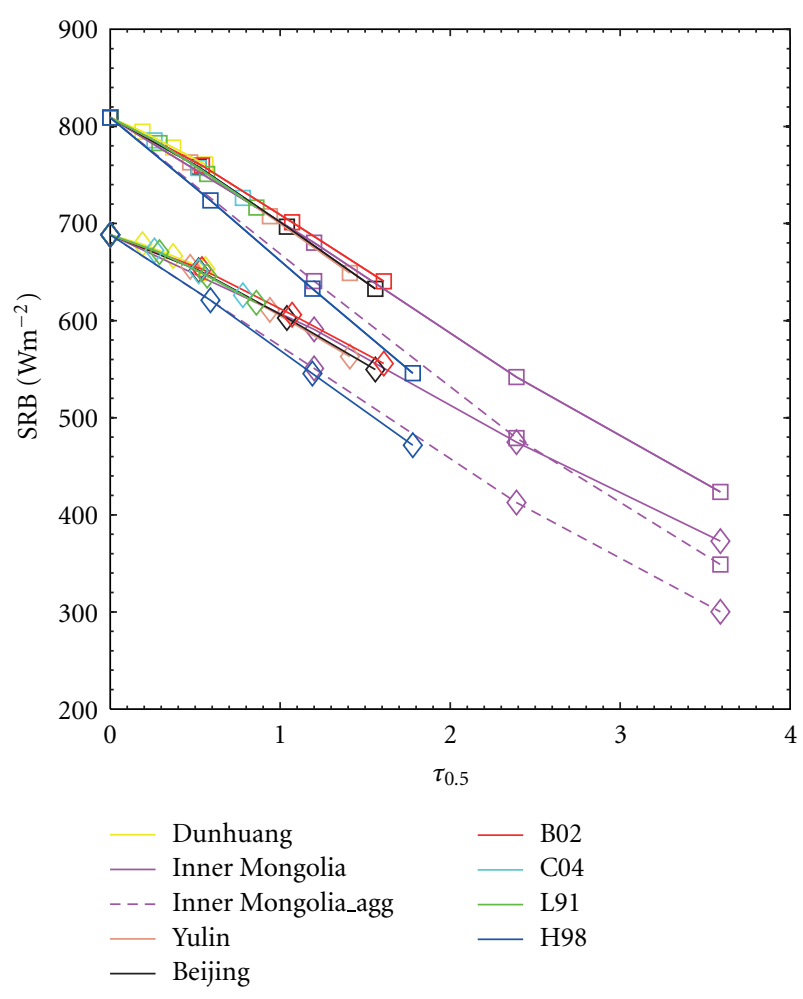

FIGURE 8: Surface radiative balance (SRB) over the cropland-2 (squares) and grassland (diamonds) for considered dust cases (at three dust loadings).

spectral behaviors in the PAR versus near-IR. Our PAR/SW $\mathrm{dn}$ value $(0.45)$ is slightly lower than that $(0.45-0.50)$ reported by Frouin and Pinker [45] and is close to the value (0.4430.445 ) reported by Jacovides et al. [46] for soot aerosol.

3.3. Impact of Dust on Surface Radiative Balance. It is well known that dust can reduce the surface net radiation, which controls the available energy for surface turbulent fluxes and affects the surface temperature and boundary layer dynamics $[1,3]$. Figure 8 shows surface radiative balance (SRB, (3)) as a function of $\tau_{0.5}$ for the mixed layer profile case. Under clean conditions, SRB ranges from $688.4 \mathrm{Wm}^{-2}$ over grassland to $809.1 \mathrm{Wm}^{-2}$ over cropland-2. We used the same surface emissivity and temperature for all ecosystems, so this difference is chiefly due to differences in surface albedo. For dust loading of $M=250 \mu \mathrm{g} \mathrm{m}^{-3}$, the reduction in SRB over cropland-2 ranges from $-14.6 \mathrm{Wm}^{-2}$ for the Dunhuang dust case to $-128.8 \mathrm{Wm}^{-2}$ for the Inner Mongolia case and to $-168.3 \mathrm{Wm}^{-2}$ for the Inner Mongolia_agg case. The forcing efficiency in SRB $\left(\delta_{\mathrm{SRB}}\right)$ ranges from $-91.4 \mathrm{Wm}^{-2} \tau_{0.5}{ }^{-1}$ for the Dunhuang case to $-122.1 \mathrm{Wm}^{-2} \tau_{0.5}{ }^{-1}$ for the Inner Mongolia_agg case. As expected, the large differences in the dust forcing in the $\mathrm{SRB}\left(\mathrm{RF}_{\mathrm{SRB}}\right)$ and $\delta_{\mathrm{SRB}}$ are due to the differences in the dust optical characteristics.

When the SW and LW radiation components were examined separately, we found that the reduction in SW net radiation ranges from $-18.8 \mathrm{Wm}^{-2}$ for the Dunhuang dust case to $-140.6 \mathrm{Wm}^{-2}$ for the Inner Mongolia case and to
$-182.7 \mathrm{Wm}^{-2}$ for the Inner Mongolia_agg case. The forcing efficiency in the SW ranges from $-110.1 \mathrm{Wm}^{-2} \tau_{0.5}{ }^{-1}$ for the Dunhuang case to $-139.4 \mathrm{Wm}^{-2} \tau_{0.5}{ }^{-1}$ for the L91 case. These values are higher than those $\left(-73.0 \pm 9.6 \mathrm{Wm}^{-2} \tau_{0.5}{ }^{-1}\right)$ reported by Bush and Valero [44]. We also found that the LW positive forcing compensates the SW reduction by about 7.9-26.4\%. In the case of elevated layer, the dust LW forcing decreased by $1.7-5.6 \mathrm{Wm}^{-2}$ because of lower temperatures associated with the elevated dust layer.

3.4. Impact of Dust on Vegetation Light Use Efficiency. In Section 3.2, we demonstrated that Asian dust can exert a substantial impact on the total PAR and its direct/diffuse partitioning. To explore the potential implications for croplands, here we consider several light use efficiency (LUE) models for different crop types (wheat, soybean, and corn) $[8,12,34,35$, 47].

It is well established that the biomass accumulation is nearly linearly related to PAR intercepted (or absorbed) by the vegetation canopy (APAR) so that the carbon assimilation rate of the canopy $\left(A_{c}\right)$ can be expressed as [48]

$$
A_{c}=\mathrm{LUE} * \mathrm{APAR}=\mathrm{LUE} * \mathrm{fPAR} * \mathrm{PAR},
$$

where the ratio of $A_{c}$ to APAR is called the light use efficiency (LUE, mol $\mathrm{CO}_{2}(\text { mol APAR })^{-1}$ ) and fPAR is the fraction of PAR absorbed by the canopy. fPAR can be readily estimated from the leaf characteristics and is currently operationally retrieved from satellite observations, for instance, MODIS (see http://modis-land.gsfc.nasa.gov/lai.html).

Observations showed that LUE increases with the in-

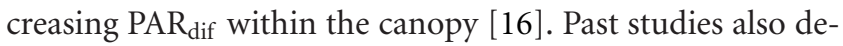
monstrated that LUE increases more or less linearly with the diffuse fraction, $\alpha[34,35,47]$. For the case of wheat canopy with a leaf area index (LAI) of 2.9, Choudhury [34] derived the LUE- $\alpha$ relationship as follows:

$$
\text { LUE }=0.0356 \alpha+0.0108 .
$$

Based on model results, Anderson et al. [35] parameterized LUE as a function of $\alpha$ for both C3 and C4 plants. For soybean (C3 plant):

$$
\mathrm{LUE}=0.025[1+0.8(\alpha-0.5)]
$$

and for corn (C4 plant):

$$
\operatorname{LUE}=0.04[1+0.3(\alpha-0.5)]
$$

Based on the modeling results of Choudhury [47] for a variety of crop and forest canopies in different climatic zones, Roderick et al. [8] derived the following LUE- $\alpha$ relationship:

$$
\mathrm{LUE}=0.024 \alpha+0.012
$$

Given that the latter is based on an ensemble of modeling cases for various vegetation types, this LUE model is not for a specific vegetation type but more generic in nature. Although LUE is expressed solely as a function of diffuse fraction of PAR, these LUE models do account (implicitly) for likely 


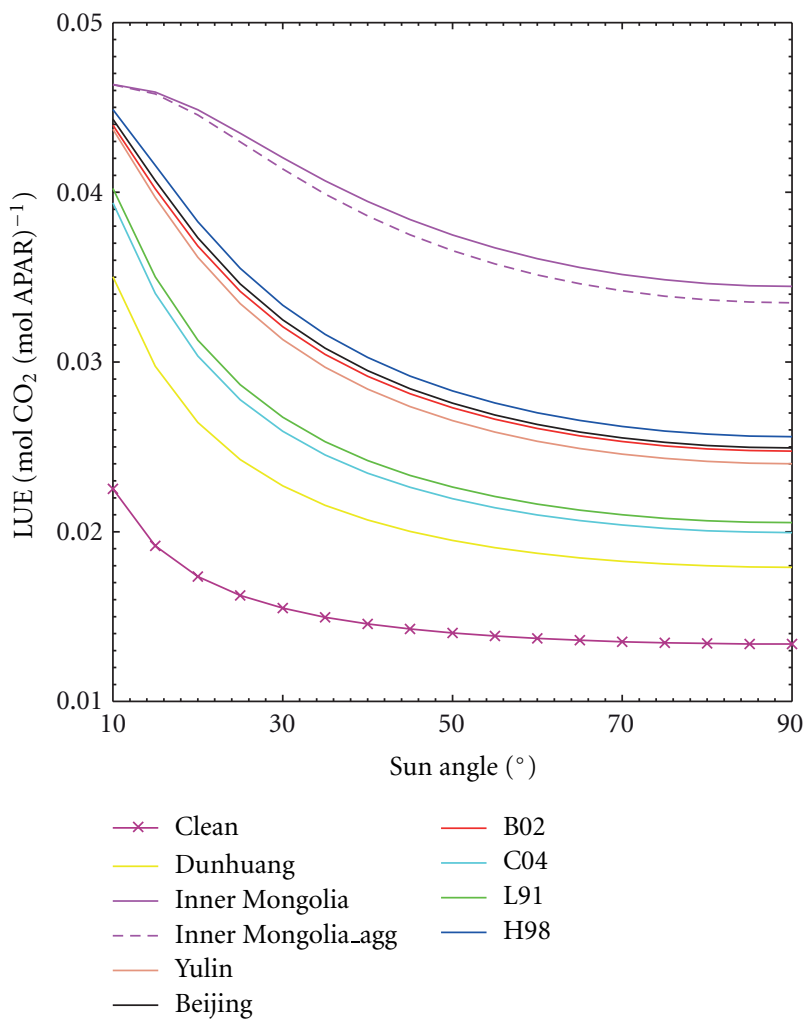

(a)

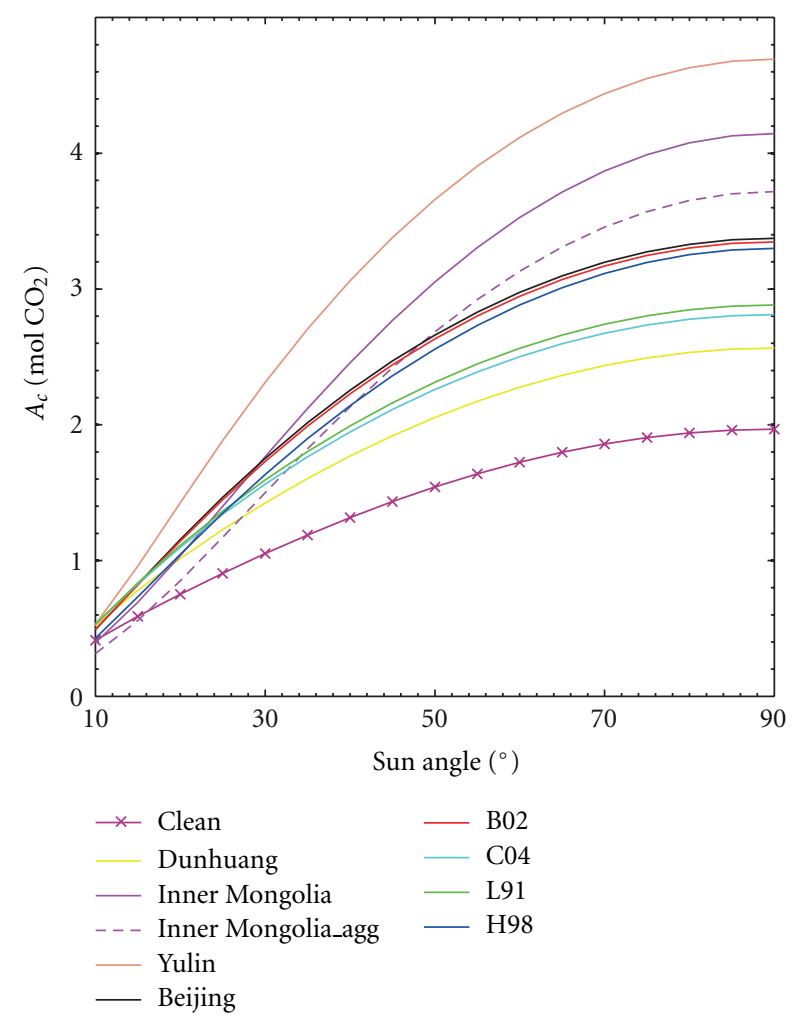

(b)

Figure 9: (a) Light use efficiency (LUE), and (b) carbon assimilation rate $\left(A_{c}\right)$ computed with the Choudhury [34] model (for wheat) as a function of sun elevation angle. Dust loading $M=$ $250 \mu \mathrm{g} \mathrm{m}^{-3}$. Surface albedo is for the cropland-2 case.
TABle 2: Comparison of past studies on the aerosol impact on PAR and plant photosynthesis in cloud-free condition.

\begin{tabular}{|c|c|c|c|c|}
\hline Study & $\begin{array}{l}\text { Data and } \\
\text { method }\end{array}$ & $\begin{array}{c}\text { Aerosol } \\
(\max . \\
\left.\tau_{0.5} / \omega_{0}\right)^{\mathrm{a}}\end{array}$ & $\begin{array}{l}\text { Ecosystem } \\
\text { (s) }\end{array}$ & $\tau_{\mathrm{ct}}$ \\
\hline $\begin{array}{l}\text { Cohan et al. } \\
{[12]}\end{array}$ & Crop models & $\begin{array}{c}\text { Urban } \\
\text { pollution } \\
(0.5 / 0.9)\end{array}$ & Crop & $\sim 0.6$ \\
\hline $\begin{array}{l}\text { Niyogi et al. } \\
{[15]}\end{array}$ & $\begin{array}{l}\text { Eddy fluxes; } \\
\text { AERONET }\end{array}$ & $\frac{-}{(0.8 /-)}$ & $\begin{array}{l}\text { Forest, } \\
\text { crop, } \\
\text { grassland }\end{array}$ & $>0.8$ \\
\hline $\begin{array}{l}\text { Yamasoe et al. } \\
{[13]}\end{array}$ & $\begin{array}{l}\text { Eddy fluxes; } \\
\text { AERONET }\end{array}$ & $\begin{array}{c}\text { Biomass } \\
\text { burning } \\
(3.0 / 0.93)\end{array}$ & $\begin{array}{l}\text { Tropical } \\
\text { rainforest }\end{array}$ & $1.5-2.0$ \\
\hline $\begin{array}{l}\text { Jing et al. } \\
{[49]}\end{array}$ & $\begin{array}{l}\text { Eddy fluxes; } \\
\text { AERONET }\end{array}$ & $\begin{array}{c}- \\
(1.2 /-)\end{array}$ & $\begin{array}{l}\text { Semiarid } \\
\text { grassland }\end{array}$ & $\begin{array}{l}\text { Not found, } \\
\text { but }>1.2\end{array}$ \\
\hline
\end{tabular}

${ }^{\mathrm{a}}$ Values in the parentheses are maximum $\tau$ and $\omega_{0}$ at $0.5 \mu \mathrm{m}$.

changes in surface radiative balance, given that the models were developed for specific environmental conditions (temperature, soil moisture, etc.).

Using the LUE models (11)-(14) and our radiation modeling results, we assessed the potential dust impact on the vegetation carbon uptake. Figure 9 presents the LUE and $A_{c}$ computed for wheat (11) under clean and dusty $(M=$ $250 \mu \mathrm{g} \mathrm{m}^{-3}$ ) conditions. Apparently, LUE has the same dependence on sun elevation angle as $\alpha$ (see Figure 7). As the sun angle increases, LUE decreases and begins to level off when sun angle $>70^{\circ}$. In contrast, Figure 9 (b) shows that the gross photosynthetic rate $A_{c}$ increases with the sun angle. Generally, $A_{c}$ is larger in all dust cases compared to clean conditions, except that at low sun elevation angles when the diffuse fraction is already very high, the reduction in PAR by dust can lead to a decrease in $A_{c}$, in this case the Inner Mongolia_agg dust case for sun angle $<15^{\circ}$. Although the Inner Mongolia dust case leads to the largest LUE, the largest $A_{c}$ is associated with the Yulin case. This is due to the fact that the Inner Mongolia case causes a large reduction in PAR, whose effect dominates the increase in $\alpha$ and LUE.

Previous studies reported that the plant gross photosynthesis can reach a maximum at a critical aerosol loading corresponding to a certain optical depth, $\tau_{\mathrm{ct}}$ (see Table 2 ). When the aerosol optical depth drops below $\tau_{\mathrm{ct}}$, the majority of shaded leaves receive very low sunlight while the sunlit leaves are light saturated. On the other hand, when the aerosol optical depth exceeds $\tau_{\mathrm{ct}}$, most sunlight is attenuated such that the plant is light-starved. Using the LUE model of Roderick et al. [8], we calculated $A_{c}$ as a function of dust loading for all dust cases, as shown in Figure 10. There are noticeable differences in the behavior of $A_{c}$ : it decreases with increasing dust loading for the Inner Mongolia and Inner Mongolia_agg dust cases, while in the OPAC case, $A_{c}$ increases with dust loading (up to $M=500 \mu \mathrm{g} \mathrm{m}^{-3}$ ) and then decreases. For all other dust cases, $A_{c}$ increases with dust loading. These can be explained by the fact that the aerosol impact on the plant carbon uptake depends on a balance between the reduction in PAR and the increase in $\mathrm{PAR}_{\mathrm{dif}}$. For example, the Inner Mongolia dust case has a much 


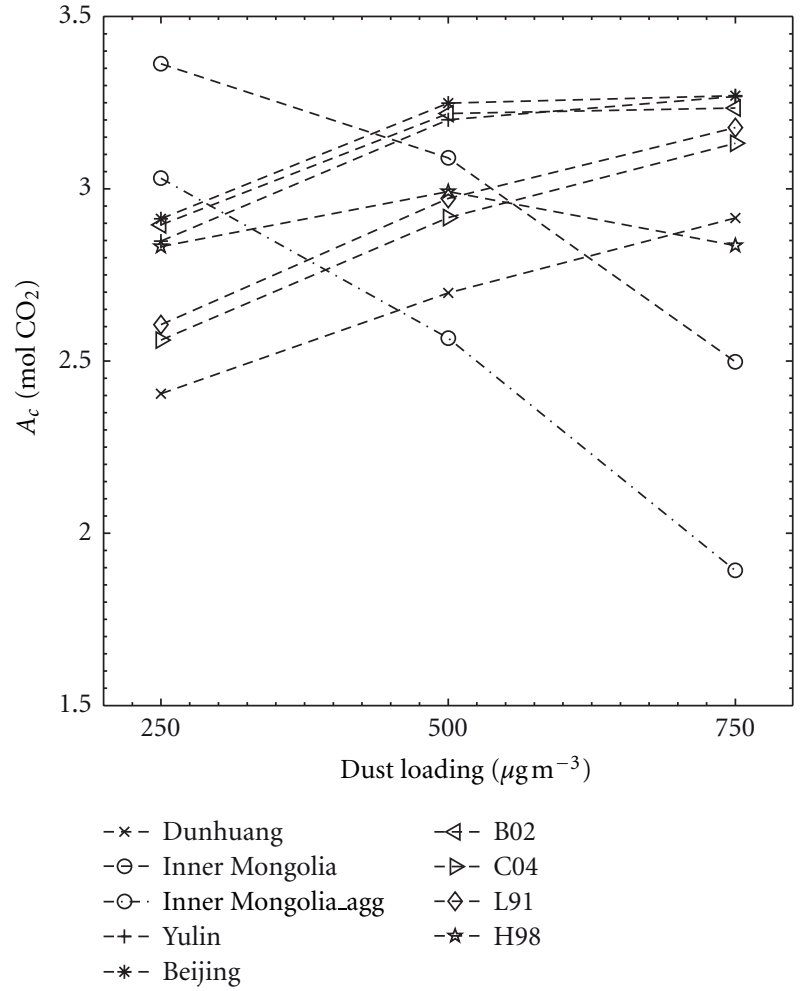

FIGURE 10: Carbon assimilation rate calculated with the LUE model of Roderick et al. [8] as a function of dust loading for all dust cases.

larger extinction coefficient than other cases, such that at dust loading $M=250 \mu \mathrm{g} \mathrm{m}^{-3}$, resultant dust optical depth exceeds the optimum value for gross photosynthesis.

Figure 11 presents LUE and $A_{c}$ computed with the LUE models using (11) $-(14)$ at sun elevation angle $=90^{\circ}$ for dust loading $M=250 \mu \mathrm{g} \mathrm{m}^{-3}$. Due to the fact that corn (C4 plant) has a higher light saturation point and is less sensitive to changes in PAR dif than C3 plants [47], the LUE and $A_{c}$ values for corn are higher and less sensitive to the dust optical properties compared to other plant types. In addition, for certain crop type $A_{c}$ peaks at different values depending on the dust case, for example, $A_{c}$ of soybean and wheat reaches the maximum for the Inner Mongolia $\left(3.4 \mathrm{~mol} \mathrm{CO}_{2}(\mathrm{~mol} \mathrm{APAR})^{-1}\right)$ and Yulin $\left(5.2 \mathrm{~mol} \mathrm{CO}_{2}(\mathrm{~mol} \mathrm{APAR})^{-1}\right)$ dust cases, respectively. Thus, our results demonstrate that the dust impact on the PAR and plant photosynthesis depends on both the dust properties and ecosystem type (e.g., C3 versus C4 crops).

\section{Conclusions and Discussions}

In this study, we investigated the dust impact on the PAR and surface radiative balance (SRB) considering conditions representative of dryland ecosystems in East Asia. The spectral (from the UV to thermal IR) optical characteristics of Asian dust were computed based on representative size-resolved mineralogical composition and remote sensing retrievals of dust size distributions. MODIS narrowband albedo products along with the USGS spectroscopy library data were used to

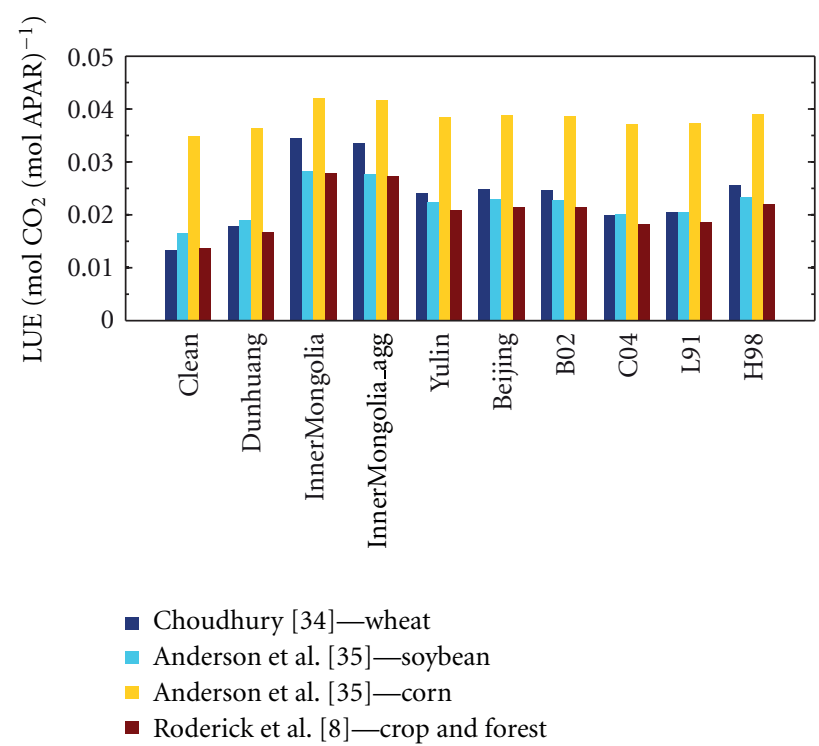

(a)

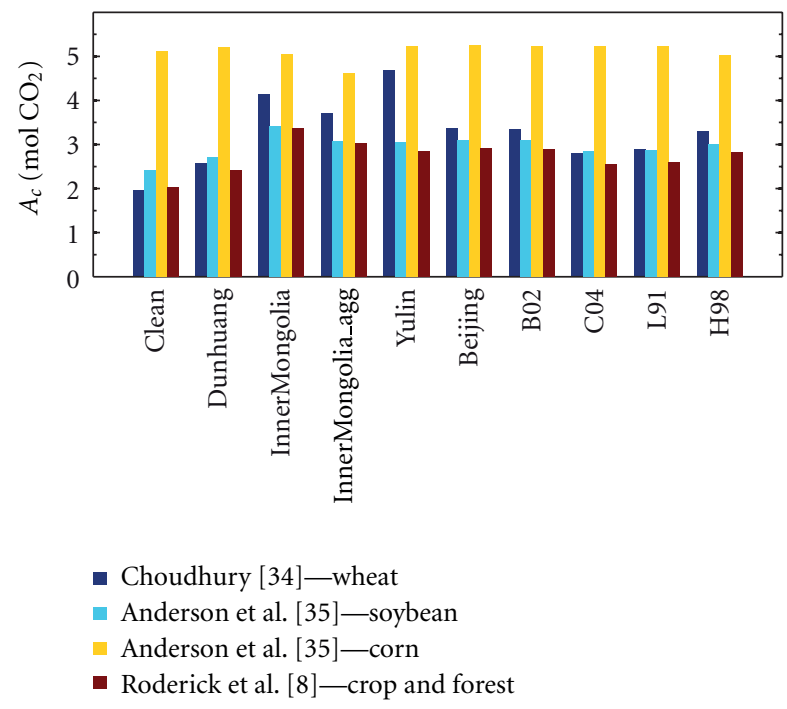

(b)

Figure 11: (a) Light use efficiency (LUE), and (b) carbon assimilation rate $\left(A_{c}\right)$ computed for clean and dust conditions (sun elevation angle $=90^{\circ}$ ) using the LUE models of $[8,34,35]$.

reconstruct the spectral surface albedo of different ecosystems in East Asia. These albedo data and dust optical models were incorporated in the radiative transfer model SBDART, which was used to investigate the dust-induced changes in PAR, and SRB in terms of forcing and its efficiency. The radiative transfer modeling results were analyzed with several LUE models to examine the implications of the dust radiative impact on the plant gross photosynthetic rate.

For a representative Asian dust composition, our results demonstrate significant variations in the optical characteristics in terms of both the magnitude and spectral dependence caused by variations in size distribution. For instance, at $0.5 \mu \mathrm{m}$, the normalized extinction coefficient ranges from $1.9 \times 10^{-4}$ to $1.2 \times 10^{-3} \mathrm{~km}^{-1}\left(\mu \mathrm{g} \mathrm{m}^{-3}\right)^{-1}$ and 
the single scattering albedo ranges from 0.88 to 0.93 for Asian dust cases (Figure 4). The highest absorption case (Inner Mongolia_agg), which only contains iron-oxide clay aggregates, gives the lowest $\omega_{0}(0.5 \mu \mathrm{m})$ of 0.88 and so does the OPAC dust model. However, the OPAC dust has too low $\omega_{0}$ values across the SW spectrum compared to Asian dust cases. Comparison with the OPAC bulk dust optical model stresses the limitations of this model in representing regional dust optics, in particular, Asian dust. This also demonstrates the need and advantage of representing the dust mineralogy and size distribution covering fine and coarse modes in assessments of the dust radiative impact.

The dust-induced changes in the total PAR, diffuse PAR and SRB are found to exhibit large variations over the dryland ecosystems, depending on the dust optical properties and the surface albedo. The estimated range of the forcing efficiency of Asian dust in SRB is from -68.8 to $-122.1 \mathrm{Wm}^{-2} \tau_{0.5}{ }^{-1}$ (Figure 8 ), while in the total PAR it ranges from -67.7 to $-82.2 \mathrm{Wm}^{-2} \tau_{0.5}{ }^{-1}$. The OPAC and Inner Mongolia_agg give the largest absolute value (about $-110 \mathrm{Wm}^{-2} \tau_{0.5}{ }^{-1}$ in total PAR) caused by higher absorption in these two cases. They also give the smallest increase in the diffuse component of PAR compared to the Asian dust cases (Figure 6(b)). Similar to other aerosol types, the ratio of total PAR to downwelling shortwave flux remains nearly constant $(0.45 \pm 4 \%)$ (Figure $7(\mathrm{~b}))$. However, the diffuse faction of PAR exhibits significant variations among considered Asian dust cases (Figure 7(a)).

Using the light use efficiency (LUE) models for several types of crops (wheat, soybean, and corn), we estimated the influence of dust-induced changes in PAR on the plant photosynthesis. We found that the dust impact on the vegetation gross photosynthetic rate is also a strong function of dust optical properties but differs among crop types. The plant photosynthetic rate was enhanced under a low dust loading, but was decreased when dust loading exceeded a certain optimal level. This behavior is consistent with previous studies of other types of aerosols that identified a critical aerosol optical depth. We demonstrate, however, that the critical optical depth depends on both the loading and size distribution of dust. In particular, the relative proportion of fine and coarse modes is a key factor controlling the normalized $K_{\text {ext }}(\lambda)$ so that the same dust loading will result in different optical depth depending on the size distribution considered (see Figure 5). Thus, in the case of dust aerosol, both loading and size distribution will need to be considered in determining the optimal regime of plant photosynthesis.

Given that the diffuse radiation fertilization is due to the fact that more scattered sunlight reaches shaded leaves, the extent of this effect on vegetation also depends on LAI. The lower the LAI the less the effect of the dust-enhanced diffuse radiation. Wohlfahrt et al. [49] provided observational evidence by showing that temperate mountain grassland is less sensitive to the diffuse radiation when the green area is low. They suggested that biomes with LAI $<2$ such as desert shrublands exhibit little sensitivity to diffuse PAR. Jing et al. [50] also showed that semiarid grassland exhibits no fertilization effect to the aerosol-enhanced diffuse PAR that is likely to be due to the low LAI and low light saturation point of grassland. However, dust can be transported downwind for thousands of kilometers affecting large regions with vegetation having higher LAI values.

In addition to diffuse PAR and dust-induced changes in SRB, there are a number of important factors that can significantly affect the vegetation functioning including photosynthesis, respiration, and transpiration processes. Under aerosol-laden conditions, concurrent variations in leaf/soil temperature and humidity may occur that can amplify the diffuse PAR effect [16]. Specifically, due to less incoming solar radiation, lowering leaf/soil temperature could depress the leaf/soil respiration, while a lower vapor pressure deficit tends to enhance the stomatal conductance and leaf-air exchanges. These environmental changes can exert either significant $[13,14,17,49]$ or negligible [50] effects on the canopy photosynthesis. Under certain conditions, the changes in the environmental factors can overcome the effect of diffuse PAR. Steiner and Chameides [17] showed that under high-irradiance condition, the presence of aerosol reduces the incoming sunlight and leaf temperature down to an optimum level and thus enhances the photosynthesis, in which case the effect of increased diffuse PAR is negligible. Accounting for these different mechanisms will require an earth system framework that couples biosphere with the physical climate system. We suggest that improved representation of dust that takes into account size-resolved composition of fine and coarse modes will be needed to provide more accurate assessments of how dust-induced changes in the radiation regime affect the ecosystem functioning and the role of these processes in overall land-atmosphere interactions.

\section{Acknowledgment}

This work was partially funded by the NASA LCLUC Program.

\section{References}

[1] K. S. Carslaw, O. Boucher, D. V. Spracklen et al., "A review of natural aerosol interactions and feedbacks within the earth system," Atmospheric Chemistry and Physics, vol. 10, no. 4, pp. 1701-1737, 2010.

[2] I. N. Sokolik and O. B. Toon, "Incorporation of mineralogical composition into models of the radiative properties of mineral aerosol from uv to ir wavelengths," Journal of Geophysical Research D, vol. 104, no. 8, pp. 9423-9444, 1999.

[3] M. Mallet, P. Tulet, D. Serca et al., "Impact of dust aerosols on the radiative budget, surface heat fluxes, heating rate profiles and convective activity over west africa during march 2006," Atmospheric Chemistry and Physics, vol. 9, no. 18, pp. 71437160, 2009.

[4] T. Takemura, T. Nakajima, A. Higurashi, S. Ohta, and N. Sugimoto, "Aerosol distributions and radiative forcing over the Asian Pacific region simulated by spectral radiation-transport model for aerosol species (SPRINTARS)," Journal of Geophysical Research D, vol. 108, no. 8659, 10 pages, 2003.

[5] J. Huang, Q. Fu, J. Su et al., "Taklimakan dust aerosol radiative heating derived from calipso observations using 
the fu-liou radiation model with Ceres constraints," Atmospheric Chemistry and Physics, vol. 9, no. 12, pp. 4011-4021, 2009.

[6] A. M. Vogelmann, P. J. Flatau, M. Szczodrak, K. M. Markowicz, and P. J. Minnett, "Observations of large aerosol infrared forcing at the surface," Geophysical Research Letters, vol. 30, no. 1655, 4 pages, 2003.

[7] K. M. Markowicz, P. J. Flatau, A. M. Vogelmann, P. K. Quinn, and E. J. Welton, "Clear-sky infrared aerosol radiative forcing at the surface and the top of the atmosphere," Quarterly Journal of the Royal Meteorological Society, vol. 129, no. 594, pp. 2927-2947, 2003.

[8] M. L. Roderick, G. D. Farquhar, S. L. Berry, and I. R. Noble, "On the direct effect of clouds and atmospheric particles on the productivity and structure of vegetation," Oecologia, vol. 129, no. 1, pp. 21-30, 2001.

[9] L. Gu, D. D. Baldocchi, S. C. Wofsy et al., "Response of a deciduous forest to the mount pinatubo eruption: enhanced photosynthesis," Science, vol. 299, no. 5615, pp. 2035-2038, 2003.

[10] W. L. Chameides, H. Yu, S. C. Liu et al., "Case study ofthe effects of atmospheric aerosols and regional haze on agriculture: an opportunity to enhance crop yields in china through emission controls?" Proceedings of the National Academy of Sciences of the United States of America, vol. 96, no. 24, pp. 13626-13633, 1999.

[11] M. H. Bergin, R. Greenwald, J. Xu, Y. Berta, and W. L. Chameides, "Influence of aerosol dry deposition on photosynthetically active radiation available to plants: a case study in the yangtze delta region of china," Geophysical Research Letters, vol. 28, no. 18, pp. 3605-3608, 2001.

[12] D. Cohan, J. Xu, R. Greenwald, M. Bergin, and W. Chameides, "Impact of atmospheric aerosol light scattering and absorption on terrestrial net primary productivity," Global Biogeochemical Cycles, vol. 16, no. 1090, 12 pages, 2002.

[13] M. Yamasoe, C. Von Randow, A. Manzi, J. Schafer, T. Eck, and B. Holben, "Effect of smoke and clouds on the transmissivity of photosynthetically active radiation inside the canopy," Atmospheric Chemistry and Physics, vol. 6, no. 6, pp. 16451656, 2006.

[14] T. Matsui, A. Beltrán-Przekurat, D. Niyogi, R. A. Pielke Sr., and M. Coughenour, "Aerosol light scattering effect on terrestrial plant productivity and energy fluxes over the eastern united states," Journal of Geophysical Research D, vol. 113, Article ID D14S14, 17 pages, 2008.

[15] D. Niyogi, H. Chang, V. Saxena et al., "Direct observations of the effects of aerosol loading on net ecosystem $\mathrm{CO}_{2}$ exchanges over different landscapes," Geophysical Research Letters, vol. 31, Article ID L20506, 5 pages, 2004.

[16] L. Gu, D. Baldocchi, S. B. Verma et al., "Advantages of diffuse radiation for terrestrial ecosystem productivity," Journal of Geophysical Research D, vol. 107, no. 4050, 23 pages, 2002.

[17] A. L. Steiner and W. L. Chameides, "Aerosol-induced thermal effects increase modelled terrestrial photosynthesis and transpiration," Tellus B, vol. 57, no. 5, pp. 404-411, 2005.

[18] R. Arimoto, Y. J. Kim, Y. P. Kim et al., "Characterization of asian dust during ACE-Asia," Global and Planetary Change, vol. 52, no. 1-4, pp. 23-56, 2006.

[19] I. N. Sokolik, D. Winker, G. Bergametti et al., "Introduction to special section: outstanding problems in quantifying the radiative impacts of mineral dust," Journal of Geophysical Research D, vol. 106, no. 16, pp. 18015-18027, 2001.
[20] M. Yoshioka, N. Mahowald, A. Conley et al., "Impact of desert dust radiative forcing on sahel precipitation: relative importance of dust compared to sea surface temperature variations, vegetation changes, and greenhouse gas warming," Journal of Climate, vol. 20, no. 8, pp. 1445-1467, 2007.

[21] E. Patterson, "Optical properties of the crustal aerosol-relation to chemical and physical characteristics," Journal of Geophysical Research, vol. 86, pp. 3236-3246, 1981.

[22] I. N. Sokolik, A. Andronova, and T. C. Johnson, "Complex refractive index of atmospheric dust aerosols," Atmospheric Environment A, vol. 27, no. 16, pp. 2495-2502, 1993.

[23] F. Volz, "Infrared optical constants of ammonium sulfate, sahara dust,volcanic pumice, and flyash," Applied Optics, vol. 12, no. 3, pp. 564-568, 1973.

[24] M. Hess, P. Koepke, and I. Schult, "Optical properties of aerosols and clouds: the software package OPAC," Bulletin of the American Meteorological Society, vol. 79, no. 5, pp. 831-844, 1998.

[25] S. Lafon, I. N. Sokolik, J. Rajot, S. Caquincau, and A. Gaudichet, "Characterization of iron oxides in mineral dust aerosols: implications for light absorption," Journal of Geophysical Research D, vol. 111, Article ID D21207, 19 pages, 2006.

[26] G. R. Jeong and I. N. Sokolik, "Effect of mineral dust aerosols on the photolysis rates in the clean and polluted marine environments," Journal of Geophysical Research D, vol. 112, Article ID D21308, 18 pages, 2007.

[27] E. A. Tsvetsinskaya, C. B. Schaaf, F. Gao, A. H. Strahler, and R. E. Dickinson, "Spatial and temporal variability in moderate resolution imaging spectroradiometer-derived surface albedo over global arid regions," Journal of Geophysical Research D, vol. 111, Article ID D20106, 10 pages, 2006.

[28] D. Waggoner and I. N. Sokolik, "Seasonal dynamics and regional features of MODIS-derived land surface characteristics in dust source regions of East Asia," Remote Sensing of Environment, vol. 114, no. 10, pp. 2126-2136, 2010.

[29] F. Gao, C. B. Schaaf, A. H. Strahler, A. Roesch, W. Lucht, and R. Dickinson, "MODIS bidirectional reflectance distribution function and albedo Climate Modeling Grid products and the variability of albedo major global vegetation types," Journal of Geophysical Research D, vol. 110, Article ID D01104, 13 pages, 2005.

[30] A. Roesch, M. Wild, R. Pinker, and A. Ohmura, "Comparison of spectral surface albedos and their impact on the general circulation model simulated surface climate," Journal of Geophysical Research D, vol. 107, no. 4221, 18 pages, 2002.

[31] P. Ricchiazzi, S. Yang, C. Gautier, and D. Sowle, "SBDART: a research and teaching software tool for plane-parallel radiative transfer in the earth's atmosphere," Bulletin of the American Meteorological Society, vol. 79, no. 10, pp. 2101-2114, 1998.

[32] Q. Fu, T. J. Thorsen, J. Su, J. M. Ge, and J. P. Huang, “Test of mie-based single-scattering properties of non-spherical dust aerosols in radiative flux calculations," Journal of Quantitative Spectroscopy and Radiative Transfer, vol. 110, no. 14-16, pp. 1640-1653, 2009.

[33] B. Yi, C. N. Hsu, P. Yang, and S. C. Tsay, "Radiative transfer simulation of dust-like aerosols: uncertainties from particle shape and refractive index," Journal of Aerosol Science, vol. 42, no. 10, pp. 631-644, 2011.

[34] B. J. Choudhury, "A sensitivity analysis of the radiation use efficiency for gross photosynthesis and net carbon accumulation by wheat," Agricultural and Forest Meteorology, vol. 101, no. 2-3, pp. 217-234, 2000.

[35] M. C. Anderson, J. M. Norman, T. P. Meyers, and G. R. Diak, "An analytical model for estimating canopy transpiration 
and carbon assimilation fluxes based on canopy light-use efficiency," Agricultural and Forest Meteorology, vol. 101, no. 4, pp. 265-289, 2000.

[36] O. Dubovik, B. Holben, T. Eck et al., "Variability of absorption and optical properties of key aerosol types observed in worldwide locations," Journal of the Atmospheric Sciences, vol. 59, no. 3, pp. 590-608, 2002.

[37] A. D. Clarke, Y. Shinozuka, V. N. Kapustin et al., "Size distributions and mixtures of dust and black carbon aerosol in asian outflow: physiochemistry and optical properties," Journal of Geophysical Research D, vol. 109, Article ID D15S09, 20 pages, 2004.

[38] G. d'Almeida, P. Koepke, and E. Shettle, Atmospheric Aerosols: Global Climatology and Radiative Characteristics, A. Deepak, Hampton, VA, USA, 1991.

[39] J. Jung, Y. J. Kim, K. Y. Lee et al., “Spectral optical properties of long-range transport Asian dust and pollution aerosols over Northeast Asia in 2007 and 2008," Atmospheric Chemistry and Physics, vol. 10, no. 12, pp. 5391-5408, 2010.

[40] T. Nakajima, M. Sekiguchi, T. Takemura et al., "Significance of direct and indirect radiative forcings of aerosols in the East China Sea region," Journal of Geophysical Research D, vol. 108, no. 8658, 16 pages, 2003.

[41] S. J. Doherty, P. K. Quinn, A. Jefferson, C. M. Carrico, T. L. Anderson, and D. Hegg, "A comparison and summary of aerosol optical properties as observed in situ from aircraft, ship, and land during ACE-Asia," Journal of Geophysical Research D, vol. 110, no. 4, Article ID D04201, 35 pages, 2005.

[42] A. D. Clarke, W. G. Collins, P. J. Rasch et al., "Dust and pollution transport on global scales: aerosol measurements and model predictions," Journal of Geophysical Research D, vol. 106, no. 23, pp. 32555-32569, 2001.

[43] S. Otto, M. De Reus, T. Trautmann, A. Thomas, M. Wendisch, and S. Borrmann, "Atmospheric radiative effects of an in-situ measured saharan dust plume and the role of large particles," Atmospheric Chemistry and Physics, vol. 7, no. 18, pp. 48874903, 2007.

[44] B. C. Bush and F. P. J. Valero, "Surface aerosol radiative forcing at gosan during the ACE-Asia campaign," Journal of Geophysical Research D, vol. 108, no. 8660, 8 pages, 2003.

[45] R. Frouin and R. T. Pinker, "Estimating photosynthetically active radiation (PAR) at the earth's surface from satellite observations," Remote Sensing of Environment, vol. 51, no. 1, pp. 98-107, 1995.

[46] C. Jacovides, F. Tymvios, D. Asimakopoulos, K. Theofilou, and S. Pashiardes, "Global photosynthetically active radiation and its relationship with global solar radiation in the eastern mediterranean basin," Theoretical and Applied Climatology, vol. 74, no. 3-4, pp. 227-233, 2003.

[47] B. J. Choudhury, "Modeling radiation-and carbon-use efficiencies of maize, sorghum, and rice," Agricultural and Forest Meteorology, vol. 106, no. 4, pp. 317-330, 2001.

[48] J. L. Monteith, "Solar radiation and production in tropical ecosystems," Journal of Applied Ecology, vol. 9, pp. 747-766, 1972.

[49] G. Wohlfahrt, A. Hammerle, A. Haslwanter, M. Bahn, U. Tappeiner, and A. Cernusca, "Disentangling leaf area and environmental effects on the response of the net ecosystem $\mathrm{CO}_{2}$ exchange to diffuse radiation," Geophysical Research Letters, vol. 35, Article ID L16805, 5 pages, 2008.

[50] X. Jing, J. Huang, G. Wang et al., "The effects of clouds and aerosols on net ecosystem $\mathrm{CO}_{2}$ exchange over semi-arid loess plateau of northwest china," Atmospheric Chemistry and Physics, vol. 10, no. 17, pp. 8205-8218, 2010. 

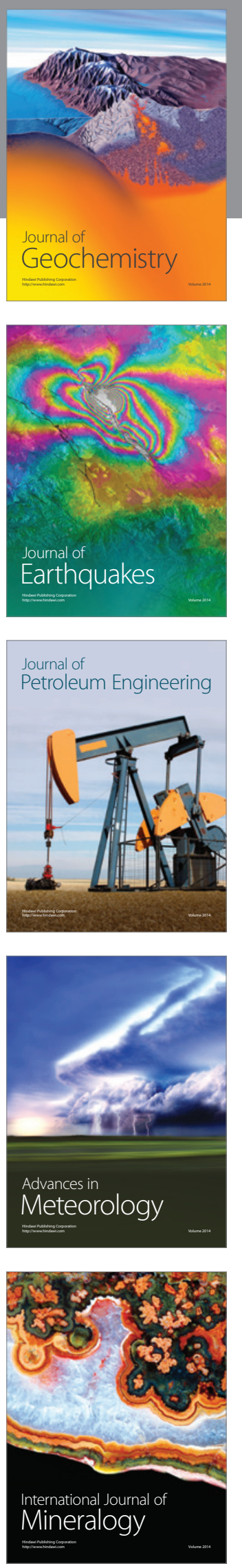
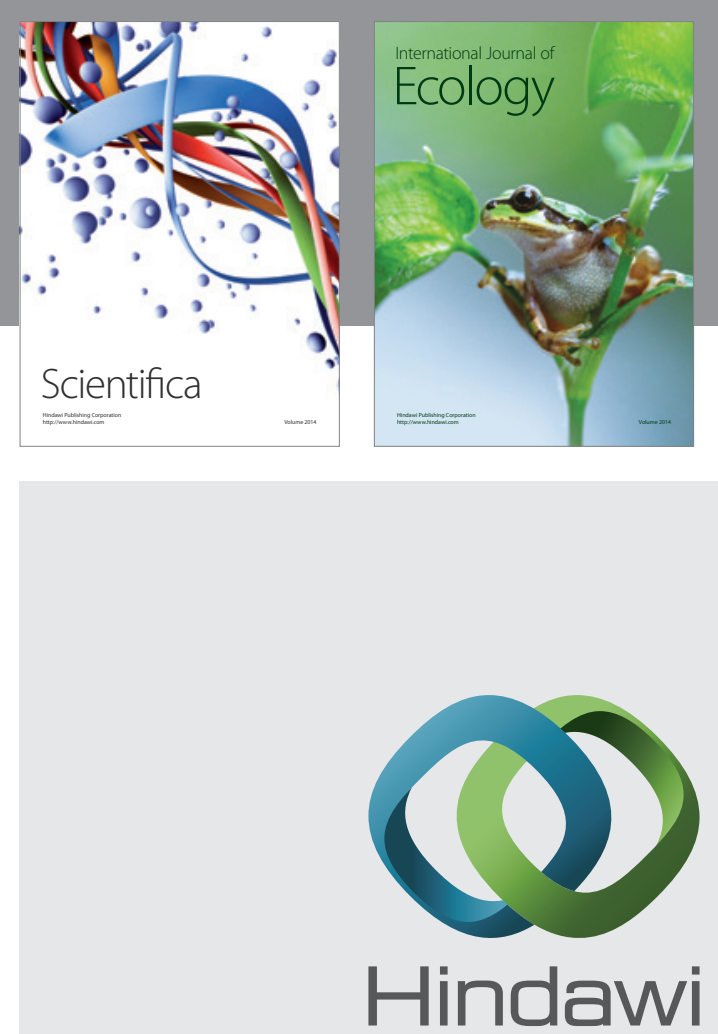

Submit your manuscripts at http://www.hindawi.com
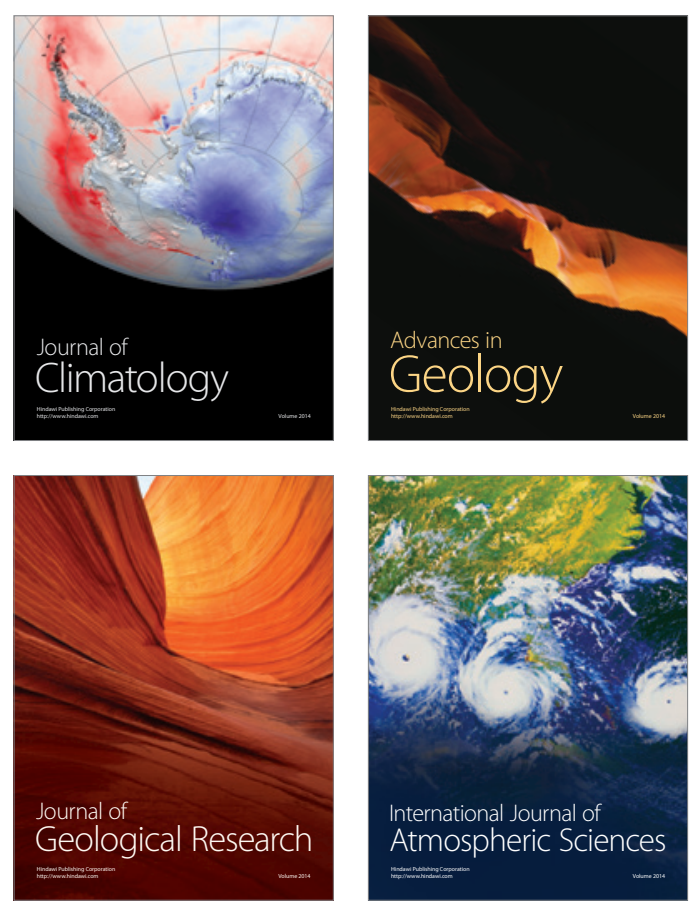
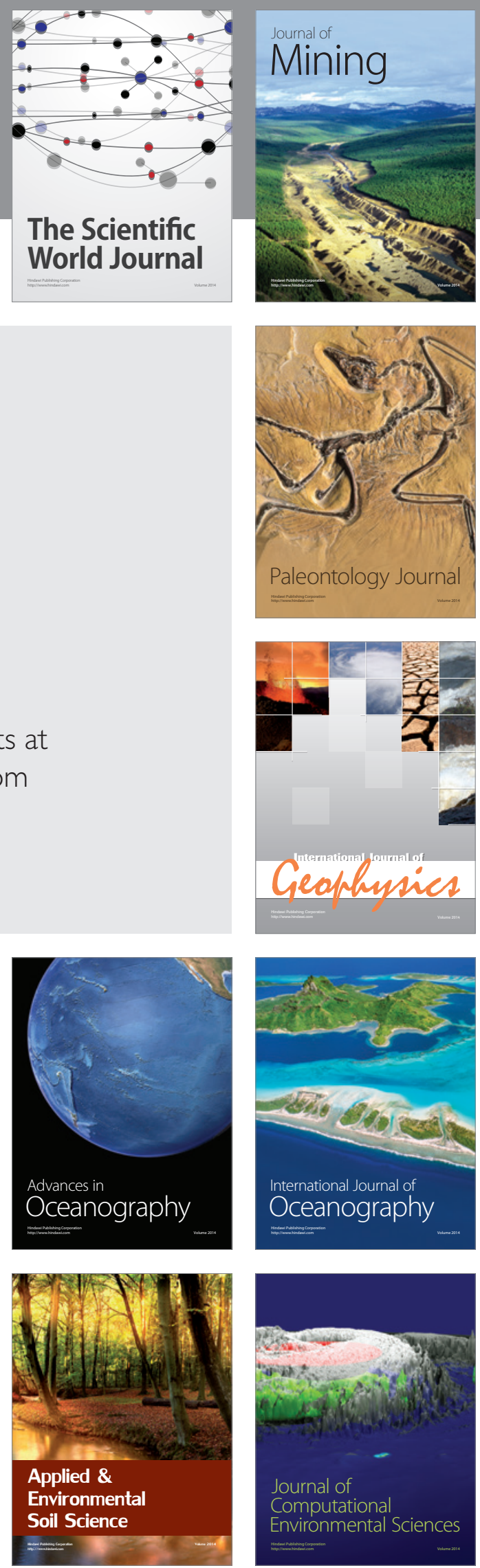